\title{
GOODS WITH EMBEDDED SOFTWARE: CONSUMER Protection 2.0 in Times of Digital Content?*
}

\author{
JASPER VEREECKEN** \\ JARICH WERBROUCK ${ }^{* * *}$
}

\section{INTRODUCTION}

Software has acquired a central role in the lives of almost anyone taking part in modern society. People buy watches that measure their blood pressure and heart pulsation, cars that slow down automatically when they get to close to the car in front, and computers with pre-installed software. However, digital content is not only dispersed via tangible media. People also acquire digital content and digital services apart from a tangible medium (mostly online). Streaming music and downloading movies are just two of the many examples.

But what if it goes wrong? What if the digital content (or services) does not work properly? Until recently, litigants had to rely on legal concepts and systems designed by the European legislature, without the latter having had special (or any) attention for the specificities of digital content or software. As a consequence, application problems are often around the corner. Section I of this contribution will bring up these problems. For a couple of years, however, the European legislature seems to be catching up with reality in the sense that multiple initiatives have been taken to (try to) develop systems that take into appropriate account the particularities of digital content. Section II will examine to what extent these new systems will entail ameliorations in comparison to the current ones, and to what extent the European legislature missed an opportunity. The focus will be more specifically on goods with embedded software. Section III will throw a glance at the present and the future, in order to conclude whether or not the envisaged adaptations will add much to a high(er) degree of consumer protection ex Article 38 of the Charter of Fundamental Rights of the European Union. Finally, Section IV will examine the enforcement of these substantive law provisions. After all, one of the most large-scale infringements on consumer law in the EU until today concerned embedded software-the Dieselgate scandal. Hence, the possibilities of the previous Consumer Sales Directive and new Goods Directive for effective enforcement of such an infringement will be examined. Emphasis will be placed on possible defects and the repercussions thereof for effective enforcement. The analysis will then look whether legislative solutions within an EU law perspective exist outside said former and current legal framework for the protection of consumer interests.

This contribution will focus specifically on the special consumeristic legislation the European legislature has supplied. It should be borne in mind, however, that the general provisions of the law of obligations still apply as well.

* This Article is based on an earlier contribution, written for the Symposium of the Consumer Law Institute held in Ghent (Belgium) on the $24^{\text {th }}$ of May 2019.

** PhD Researcher University of Antwerp and Ghent University (Joint PhD); LL.M., Ghent University Law School, 2018.

*** PhD Researcher Ghent University; LL.M., Ghent University Law School, 2017. 
The latter remain beyond the scope of the current contribution.

\section{LACK OF CONFORMITY OF DIGITAL CONTENT - DE LEGE LATA}

When we look at the situation as it stands, a distinction has to be made depending on the way in which the consumer acquires the digital content or the good in which it is incorporated. Should they acquire the digital content or the good by means of an off-premises contract or by means of a distance contract, the consumer will be entitled to rely on specific provisions foreseen in Directive 2011/83/EU (hereinafter: 'Consumer Rights Directive', 'CRD') (A.). ${ }^{1}$ Furthermore-and in the hypothesis that there is a tangible medium-he will also be able to fall back on the specific provisions concerning consumer sales as foreseen in Directive 1999/44/EC (hereinafter: 'Consumer Sales Directive', 'CSD') (B.). ${ }^{2}$ In case there is no off-premises or distance contract (i.e. the classical store visit; on-premises contracts), only the rules concerning consumer sales will apply, insofar as there is a tangible medium.

\section{A. Specific Provisions for Off-premises Contracts or Distance Contracts}

\section{Scope of Application}

Both the specific rules concerning off-premises contracts and those concerning distance contracts are applicable to sales contracts, service contracts, contracts for the supply of digital content that is not supplied on a tangible medium ('contracts for online digital content'), and contracts for the supply of water, gas, or electricity, where they are not put up for sale in a limited volume of set quantity, or of district heating. ${ }^{3}$ In this context, the first and third type of contracts are especially relevant.

Digital content is defined as 'data which are produced and supplied in digital form' (Article 2 (11) CRD). ${ }^{4}$ Digital content can be distributed both in a

1. Directive 2011/83, of the European Parliament and of the Council of 25 October 2011 on consumer rights, amending Council Directive 93/13/EEC and Directive 1999/44/EC, of the European Parliament and of the Council and repealing Council Directive 85/577/EEC and Directive 97/7/EC of the European Parliament and of the Council, 2011 O.J. (L 304) (EU). This directive entailed maximum harmonisation, meaning that the Member States could not foresee in any protection within the harmonised area, other than that foreseen by the directive.

2. Directive 1999/44, of the European Parliament and of the Council of 25 May 1999 on certain aspects of the sale of consumer goods and associated guarantees, 1999 O.J. (L 171) (EC).

3. DG JUST Guidance Document concerning Directive 2011/83, of the European Parliament and of the Council of 25 October 2011 on consumer rights, amending Council Directive 93/13/EEC and Directive 1999/44/EC and repealing Council Directive 85/577/EEC and Directive 97/7/EC of the European Parliament and of the Council, June 2014, 5.

4. See Reinhard Steennot, Art. I.8, $33^{\circ}-35^{\circ}$ WER, in Reinhard Steennot, Jules Stuyck, HENDRIK VANHEES \& EDDY WYMEERSCH, HANDELS-EN ECONOMISCH RECHT. COMMENTAAR MET OVERZICHT VAN RECHTSPRAAK EN RECHTSLEER [Commercial and economic law. Commentary with overview of case law and doctrine] 53 (Wolters Kluwer, 2016). It may concern computer programs, 
materialised (e.g. DVD or CD) and a non-materialised (e.g. downloading or streaming) way. Contracts concerning the former are deemed to be sales contracts, whereas contracts concerning the latter are held to be contracts for online digital content. The division between these two types of contracts is translated into diverging applicable provisions. Materialised digital content (digital content distributed on a tangible medium) has to be considered as a 'good' for the application of the specific provisions concerning off-premises contracts and distance contracts. ${ }^{5}$ Consequently, the contract has to be considered as a sales contract. ${ }^{6}$ It should be noted that goods with embedded software will always be considered as 'goods' in this context and that, consequently, the contract concerning its supply to consumers will always be deemed a sales contract, irrespective of the exact 'relationship' between the tangible medium and the digital content. ${ }^{7}$ In the event where the digital content is distributed in a nonmaterialised way, the contract will be a sui generis one ('a contract for online digital content'), ${ }^{8}$ for which diverging rules may exist in comparison to the ones applicable to digital content on a tangible medium.

Generally, in the event that a contract concerns digital content, the trader has to inform the consumer about the functionality, including applicable technical protection measures, and the relevant interoperability of digital content with hardware and software that the trader is aware of or that he can reasonably be expected to have been aware of (Article 6.1 (r) and (s) CRD). Moreover, in the case of digital content that is not supplied on a tangible medium, the consumer bears no cost for the supply, in full or in part where (i) the consumer has not given his prior express consent to the beginning of the performance before the end of the fourteen-day period during which he can exercise his right of withdrawal, (ii) the consumer has not acknowledged that he loses his right of withdrawal when giving his consent, or (iii) the trader has failed to provide the consumer with written confirmation of the pre-contractual information which had to be supplied initially where appropriate along with the prior express consent and the acknowledgment of the consumer that he loses his right of withdrawal

applications, games, music, videos or texts. See recital 19 CDR. As Reinhard Steennot rightly suggests, the use of the word 'and' indicates cumulativity. Consequently, it does not suffice that the date are produced or supplied in digital form.

5. Council Directive 2011/83, 2011 O.J. (L 304) 64, 66 (EU). 'Goods' are defined as 'tangible movable items' Article 2 (3) CRD.

6. 'Sales contracts' are described as 'any contract under which the trader transfers or undertakes to transfer the ownership of goods to the consumer and the consumer pays or undertakes to pay the price thereof, including any contract having as its object both goods and services.' Article 2 (5) CRD.

7. As will be shown further, this relationship will play an important role in the future in determining the applicable legislative framework.

8. Some national legislators, among which the Belgian one, have perceived these contracts for online digital content as service contracts. See Travaux Préparatoires [Preparatory documents] 2012-2013, doc. 53, 3018/001, 16. 
(Article 14.4 (b) CRD). ${ }^{9}$ Finally, the Directive also foresees in specific provisions for digital content supplied on a tangible medium: the consumer will not be able to exercise his right of withdrawal in the event of the supply of sealed audio or video recordings or sealed computer software, which were unsealed after delivery (Article 16 (i) CRD).

\section{Right of Withdrawal: Principle and Consequences}

Insofar as the contract between the consumer and the trader falls under the scope of the specific provisions concerning off-premises contracts or distance contracts, the consumer has in principle the right to withdraw from the contract during the first fourteen calendar days upon delivery of the goods. In the event of a contract concerning the sale of digital content which is not supplied on a tangible medium, however, the period starts to run from the day of the conclusion of the contract (Article $9 \mathrm{CRD}$ ). The consumer does not have to give any reason for the exercise of his right of withdrawal. Consequently it is also possible for the consumer to send back perfectly working digital content, next to digital content with a lack of conformity. ${ }^{10}$ The only thing the consumer has to do to exercise this right is sending a notification to the trader informing him of his decision to withdraw from the contract before the expiry of the withdrawal period. The burden of proof of informing the trader in time is on the consumer (Article 11 CRD).

The exercise of the right of withdrawal terminates the obligations of the parties to perform or conclude the contract (Article 12 CRD). ${ }^{11}$ The trader has to reimburse all payments received from the consumer, including costs of delivery, without undue delay and in any event not later than fourteen days from the day on which he is informed of the decision to withdraw. This reimbursement has to be carried out using the same means of payment as the consumer used for the initial transaction, unless the consumer expressly agreed otherwise. However, the trader is entitled to withhold the reimbursement until he has received the goods back or until the consumer has supplied evidence of having sent back the goods, depending on whichever is earliest, unless he offered to collect the goods himself (Article $13 \mathrm{CRD}$ ). On the side of the consumer, the obligation emerges to send back the goods or hand them over to the trader or person authorised by the trader to receive the goods, without undue delay and in any event not later than fourteen days from the day on which he has informed the trader of the withdrawal, unless the trader has offered to collect the goods himself. Only the direct costs of returning the goods are to be borne by the consumer, unless the trader failed to inform the consumer that the latter has to bear them. In the latter event, the consumer does not bear these costs. Furthermore, the consumer is in principle

9. The use of the word 'or' clearly shows that these conditions are alternative. As soon as one of these three criteria is not fulfilled, the consumer shall bear no cost.

10. In this aspect the CRD diverges from the CSD, where the consumer has to prove a lack of conformity.

11. The latter hypothesis applies in case the consumer made the proposition for the contract. 
only liable for any diminished value of the goods resulting from their handling other than what is necessary to establish the nature, characteristics, and functioning of the goods (Article $14 \mathrm{CRD}$ ).

Diverging rules apply, however, in the event that the trader omitted to correctly supply the information concerning the right of withdrawal (Article 10 CRD). In that case, the withdrawal period expires twelve months from the end of the initial withdrawal period. Should, however, the trader provide the consumer with the correct information concerning the right of withdrawal within this extended period, the withdrawal period expires fourteen days after the day upon which the consumer receives that information. Another consequence of the omission to correctly supply the information concerning the right of withdrawal, the consumer is in any event not liable for any diminished value of the goods, even if this diminished value is the result of their handling other than what is necessary to establish their nature, characteristics, and functioning (Article 14.2 $\mathrm{CRD}$ ). In case there is no right of withdrawal for the consumer, the omission to inform the consumer thereof is not sanctioned.

\section{Right of Withdrawal: Exceptions}

The Directive prescribes some binding exceptions in relation to the aforementioned principle, where the consumer has no right of withdrawal (Article 16 CRD). Given the maximum harmonisation aimed at by the Directive, it is no longer possible for national legislators to give extra protection to consumers within the harmonised area (e.g. by not implementing certain exceptions, or by restricting their conditions of applicability). Neither is it possible to add new exceptions to the limitative list foreseen in the Directive. ${ }^{12}$ This does not take away the possibility to adopt additional exceptions in contracts concluded between traders and consumers. ${ }^{13}$

In the context of digital content, two exceptions deserve specific mention. First of all, there is no right of withdrawal for contacts for the supply of sealed audio or video recordings or sealed computer software which were unsealed after delivery (Article 16 (i) CRD). On the contrary, the consumer retains his right of withdrawal if the seal has not been broken or if there was no seal applied. ${ }^{14}$ Evidently, 'tangible seals' first spring to mind (e.g. the strip incorporated in the

12. Reinhard Steennot, Gert Straetmans, Evelyne Terryn, Bert Keirsbilck \& Bert Wyseur, Overzicht van rechtspraak. Consumentenbescherming (2008-2014)-Marktpraktijken (2011-2014) [Overview of case law. Consumer protection (2008-2014) - Commercial practices (2011-2014)], 52 TPR 1311, 1651 (2015).

13. In this case, the provisions concerning unfair commercial practices and unfair contract clauses must be borne in mind.

14. Note that in the context of the exceptions to the right of withdrawal, no specific rules concerning the burden of proof apply. Consequently, according to actori incumbit probation the claimant has to prove his allegations. In our opinion, however, account should be taken of the fact that sometimes this might lead to the requirement of proving a negative fact (e.g. the absence of a seal). In these types of cases, reversal of the burden of proof might be justified. 
packaging of a CD or DVD). However, there is in our opinion no reason to assume that this exception should be limited to this kind of seals. At present, audio or video files are also distributed via non-tangible media (downloading, streaming, ... .) where the consumer has to enter a digital key to break a digital seal in order to get access to the actual content (e.g. the code on the back of gift cards for the App Store). Consequently, this exception is relevant both for digital content supplied on a tangible medium, as well as for digital content not supplied on a tangible medium.

The second relevant exception confines itself to digital content which is not supplied on a tangible medium. In case the performance started within the withdrawal period of fourteen days with the consumer's prior express consent and his acknowledgment that he loses his right of withdrawal, the consumer effectively loses his right of withdrawal (Article 16 (m) CRD). The consumer does maintain a right of withdrawal if one of these conditions is not fulfilled, since he then falls under the general scope of Article 9 CRD. In the latter event, the trader should have supplied information concerning this right of withdrawal ex Article 6.1 (h) CRD. Subsequently, in case the trader did not supply this information, the period expires twelve months from the end of the initial withdrawal period (Article $10 \mathrm{CRD}$ ). ${ }^{15}$ Moreover, the consumer's prior express consent and his acknowledgment that he loses his right of withdrawal have to be provided to him on a durable medium within a reasonable time after the conclusion of the distance contract, and at the latest at the time of the delivery of the goods or before the performance of the service begins (Article $8.7 \mathrm{CRD}$ ). Insofar as it concerns off-premises contracts, the trader has to supply the consumer with a copy of the signed contract or the confirmation of the contracts on paper or, if the consumer agrees, on another durable medium, including-where applicable-the confirmation of the consumer's prior express consent and acknowledgment that his right of withdrawal ceases to exist (Article 7.2 CRD). In case of supply, in full or in part, of digital content which is not supplied on a tangible medium, the consumer bears no cost when he has not given his prior express consent for the beginning of the performance before the end of the initial withdrawal period. The same holds true if he has not acknowledged that he loses his right of withdrawal when giving this consent or if the trader failed to provide the aforementioned confirmation (Article 14.4, (b) CRD). ${ }^{16}$ Evidently, the

15. See Reinhard Steennot, Art. VI.48 WER, in R. Steennot, J. Stuyck, H. VAnhees \& E. WYMEERSCH, supra note 4, at 178. More concrete this means that if not all conditions are met for the exception to apply, and if the trader did not inform the consumer properly concerning the right of withdrawal, which exists in the latter case, the period is prolonged to twelve months and fourteen days. This situation has to be clearly distinguished from the general rule that the lack of information concerning the absence of a right of withdrawal ex Article 16 CRD does not lead to the coming into existence of a right of withdrawal or the prolongation of such right. Only the pre-contractual liability of the trader will in this case be at stake. Whereas most exceptions enacted in Article 16 CRD do not require for their application that the consumer is informed about their existence, Article $16(\mathrm{~m})$ does require this.

16. It should be noted that, if the former two conditions are met cumulatively (i.e. the 
consumer has to send back the (non-materialised) digital content. ${ }^{17}$

\section{Application Problems of the Current Legislative Framework}

Now that some guidance has been given concerning the current legislative framework for off-premises and distance contracts, some deficiencies can be uncovered.

First of all, a period of fourteen days from the day of delivery is in some cases (very) short to establish the nature, characteristics, and (potentially defective) functioning of goods. Should, for example, digital content be bought as a gift, the risk exists that by the time the recipient of the gift receives (and thus gets the chance to assess) it, the period for withdrawal has already expired. ${ }^{18}$ Moreover, it is possible (maybe even normal) for certain digital content that it takes a while before the consumer operates/can operate all functionalities. The consumer often 'discovers' the possibilities. Should it turn out after a period (e.g. three weeks) that a certain application does not function, it would already be too late for the consumer to withdraw from the contract. Subsequently, it is clear that the right of withdrawal cannot intercept the non-existence of a guarantee. This should not surprise, however, since the right of withdrawal is not meant for these types of situations. Nevertheless, as we will see further on, the Consumer Sales Directive does not apply in an important share of the situations where digital content is involved (more precisely, the supply of digital content which is not supplied on a tangible medium). In this hypothesis, the right of withdrawal might be the only remaining straw to clutch at. ${ }^{19}$

On the other side of the spectrum, a withdrawal period of fourteen days may in certain instances be too long, more specifically against the background of illegal copying and spreading of digital content followed by the exercise of the right of withdrawal. However, it should be noted that in addition to the digital possibilities to make illegal copying and spreading impossible, the Directive provides two exceptions on the right of withdrawal that can be relied on by the trader.

Finally, the question arises of what must happen if digital content is being

consumer consented expressly with the beginning of the performance before the initial period expires and the consumer acknowledged the loss of the right of withdrawal) the third condition becomes irrelevant. After all, in this hypothesis there is no right of withdrawal ex Article 16 (m).

17. The question arises as how this has to be done, since it concerns the supply of digital content which is not supplied on a tangible medium. The content may already have been saved somewhere by the consumer. Should the content function via or under the form of an online platform or access thereto, the trader could evidently cut of the access of the consumer to this platform.

18. If, for example, Edward orders a smartphone via Amazon to give to Elsie as a Christmas present, which is delivered on $10^{\text {th }}$ December, the last day on which the right of withdrawal might be exercised with success would be $24^{\text {th }}$ December.

19. Apart from the general law of obligations, that is. As indicated above, however, the latter falls out of the scope of the current contribution. 
updated. Depending on the circumstances, the update might be considered as a new off-premises or distance contract, or as the fulfilment by the trader of an obligation flowing from the initial contract. Consequently, it can be questioned whether or not a new withdrawal period starts to run from the day of the update. The provisions seem at first sight flexible enough to be employed in the context of software updates, though specific provisions might have been in place in order to avoid legal uncertainty.

\section{B. Specific Provisions for Consumer Sales Contracts}

\section{Scope of Application}

The specific provisions on consumer sales apply to contracts of sale of (nearly) $^{20}$ all tangible movable items (i.e. consumer goods) by a seller to a consumer, as well as to contracts for the supply of such items to be manufactured or produced (Article 1 CSD).

Contrary to the Consumer Rights Directive, the Consumer Sales Directive does not contain specific provisions concerning digital content. ${ }^{21}$ Once again, however, we can rely on the summa divisio between digital content supplied on a tangible medium on the one side, and digital content not supplied on a tangible medium on the other side. Since the latter is by definition not distributed on a tangible medium, and is thus not incorporated in a tangible movable item (e.g. CD, DVD, computer, ... .), this entire category of digital content-to which belong among other things streamed and downloaded data-falls out of the scope of application of the provisions on consumer sales. ${ }^{22}$ Digital content supplied on a

20. Goods sold by way of execution or otherwise by authority of law, water and gas where they are not put up for sale in a limited volume or set quantity and electricity fall out of the scope of application.

21. It should be noted, however, that given the minimum harmonisation aimed at by the Consumer Sales Directive, Member States were/are allowed to incorporate specific provisions in the context of digital content, similar to the ones adopted by the European legislator. Whereas some Member States have done so (e.g. the Netherlands), others did not (e.g. Belgium).

22. Caroline Cauffman \& Alain Verbeke, Een jaar wet consumentenkoop [One year Consumer Sales Act], in Bernard Tilleman \& Alain Verbeke, Themis 32 - Bijzondere OVEREENKOMSTEN [Themis 32 - Specific Contracts] 25, 29 (die Keure 2005); Bernard Tilleman, Consumentenkoop [Consumer sales], in Bernard Tilleman, Overeenkomsten. Deel 2. Bijzondere overeenkomsten. A. Verkoop. Deel 2. Gevolgen van de koop 577 [Contracts. Part 2. Specific Contracts. A. Sales. Part 2. Consequences of a sales contract], 581, (KLUwER 2012); Jules Stuyck, Bijzondere overeenkomsten en economisch recht [Specific contracts and economic law], in X., XXXIVste Postuniversitaire Cyclus Willy Delva - Bijzondere OVEREENKOMSTEN [XXXIVth postgraduate cycle Willy Delva - Specific contracts] (2007-2008) 8, (Wolters Kluwer 2008); Reinhard Steennot, Art. 1649bis BW, in ERIC DiriX \& AloÏs VAN OEVELEN, BIJZONDERE OVEREENKOMSTEN. ARTIKELSGEWIJZE COMMENTAAR MET OVERZICHT VAN RECHTSPRAAK EN RECHTSLEER [Specific contracts. Commentary with overview of case law and doctrine] 19, 28, (Wolters Kluwer 2015). As indicated, given the minimum harmonisation aimed 
tangible medium, to which category goods with embedded software belong per definition, does fall under the scope of application of the Directive, irrespective of the relationship between the digital content itself on the one hand and the tangible movable item which serves as medium on the other hand.

\section{Lack of Conformity of Consumer Goods}

Sellers have to deliver goods in conformity with the contract of sale. This is the case if the goods (i) comply with the description given by the seller and possess the qualities of the goods that the seller holds out to the consumer as a sample or model, (ii) are fit for any particular purpose for which the consumer requires them and which he made known to the seller at the time of conclusion of the contract and which the seller has accepted, (iii) are fit for the purposes for which goods of the same type are normally used, and (iv) show the quality and performance which are normal in goods of the same type and which the consumer can reasonably expect, given the nature of the goods and taking into account any public statements on the specific characteristics of the goods made about them by the seller, the producer or his representative, particularly in advertising or on labelling (Article 2.1 in conjunction with $2.2 \mathrm{CSD}$ ). ${ }^{23},{ }^{24}$ Moreover, a lack of conformity for which the seller is liable will also occur if there is an incorrect installation of the consumer goods if the installation forms part of the contract of sale of the goods and the goods were installed by the seller or under his responsibility. Also, if the consumer good is intended to be installed by the consumer, is installed by the consumer, and the incorrect installation is due to a shortcoming in the installation instructions, there is deemed to be a lack of conformity for which the seller is liable (Article 2.5 CSD). If for instance a smartphone is advertised with a memory capacity of 128 gigabyte, it can be reasonably expected that the consumer can call, text, surf, . . . with it. As soon as one of these applications lacks or does not work, there is a lack of conformity. Should afterwards the memory capacity turn out to be only 32 gigabyte, the smartphone will equally be deemed to be not conform with the contract.

Finally, the Directive foresees two situations in which a de facto lack of conformity is presumed not to exist de jure. More precisely, there is no lack of

at by the Directive, Member States could foresee in a similar system for digital content supplied not on a tangible medium. This has happened for instance in the Netherlands.

23. Concerning the expectations of the consumer and the information based on which he could base them, it should be kept in mind that the Consumer Rights Directive prescribes a whole range of informational duties. In the context of digital content, it is especially relevant that the seller has to supply information concerning the functionality of digital content, including applicable technical protection measures, and the relevant interoperability of digital content with hardware and software that the trader is aware of or can reasonably be expected to have been aware of.

24. The seller is not bound by public statements, however, if he shows (i) that he was not and could not reasonably have been aware of the statement in question, (ii) that by the time of conclusion of the contract the statement had been corrected or (iii) that the decision to buy the consumer goods could not have been influenced by the statement. Article 2.4 CSD. 
conformity which entails the seller's liability if, at the time the contract was concluded, the consumer was aware or could not reasonably be unaware of the lack of conformity. If, for instance, the consumer buys a second-hand car of which the seller made clear during the selling process that the software in the encapsulated GPS is dated, the consumer will not be able to make the argument that there is a lack of conformity. In addition, the seller's liability will not be endangered if the lack of conformity has its origin in materials supplied by the consumer (Article 2.3 CSD).

\section{Seller's Liability}

The seller is liable to the consumer for any lack of conformity which exists at the time of delivery of the goods and which becomes apparent within two years from the delivery of the goods (Article 3.1 in conjunction with 5.1 CSD). In case of second hand goods, the Directive foresees the possibility for Member States to provide that seller and consumer may agree a shorter time period for the liability of the seller, without it being less than one year (Article 7.1 CSD). ${ }^{25}$ The Directive does not lay down a binding period of time within which the consumer has to communicate the lack of conformity to the seller. However, it leaves the possibility to the Member States to provide that the consumer must inform the seller within a period of at least two months from the date on which he detected the lack of conformity (Article 5.2 CSD). The burden of proof of informing the seller is on the consumer, whereas (eventually) the burden of proof that the consumer did not do this within the agreed time period is on the seller. ${ }^{26}$ Though it may appear difficult to prove in which moment a lack of conformity came into existence and became apparent, the nature of goods with digital content often entails the possibility for the seller to track the exact moment in which the good was used. ${ }^{27}$ The Directive does not provide for a binding limitation period, though it leaves the possibility to do so for the Member States. This limitation period cannot expire, however, before the end of the initial two years period within which the seller is liable (Article 5.1 CSD).

In order to facilitate the application of the rules on consumer sales, the European legislator has introduced the presumption juris tantum that a lack of conformity which becomes apparent within six months of delivery of the goods existed at the time of delivery, unless this presumption is incompatible with the nature of the goods or the nature of the lack of conformity (Article 5.3 CSD) ${ }^{28}$

25. This has happened, among others, in Belgium.

26. Reinhard Steennot, Art. 1649quater BW, in ERIC Dirix \& Aloïs Van Oevelen, supra note 22 , at 66 .

27. If, for example, a smart-tv does not work anymore on February 28th and the contract of sale provides a contractual time limit of two months within which the consumer has to report the lack of conformity, the consumer who informs the seller on May 10th will eat humble pie.

28. Given the minimum harmonisation aimed at by the Directive, nothing prevented the Member States to extend the period during which this presumption is applicable. In France, for instance, the period has been extended to two years. Consequently, during the entire period of 
If, for example, someone drops his smart phone five months after delivery, due to which the screen is completely cracked and no longer useful, the nature of the lack of conformity will be incompatible with the presumption of anteriority.

\section{Hierarchy of Remedies}

The Consumer Sales Directive provides for a hierarchy of remedies on which the consumer can rely in case of liability of the seller. Only in the event where the primary remedies are not (any longer) fit to indemnify the consumer, he can demand application of the secondary remedies. Next to these specific remedies, it is also possible to claim damages from the seller.

First of all, the consumer is entitled to require the seller to repair the goods or to replace them, in both instances free of charge (the primary remedies) (Article $3.3 \mathrm{CSD}$ ). ${ }^{29}$ This repair or replacement has to be completed within a reasonable period of time and without any significant inconvenience to the consumer. In light of the latter requirement, the seller may have to supply the consumer with a replacement good (e.g. mobile phone, car, . . .). The consumer is not entirely free in his choice between repair or replacement, however, in the sense that the remedy chosen may not be impossible or disproportionate in comparison with the alternative remedy. A remedy is deemed to be disproportionate insofar as it imposes costs on the seller which are unreasonable in comparison with the alternative remedy, taking into account the value the goods would have if there was no lack of conformity, the significance of the lack of conformity, and whether or not the alternative remedy could be completed in concreto without significant inconvenience to the consumer. Should, for instance, a CD turn out to not work properly, repair will most likely be deemed disproportionate in relation to replacement. The costs of repair of the $\mathrm{CD}$ and the inconveniences caused to the consumer will namely be far higher than those of replacement. Should, on the other hand, the problem occur with a self-driving car of which certain sensors do not work properly, it is most likely that repair will (evidently depending on the circumstances) be favoured above replacement.

If the consumer is entitled to neither repair nor replacement, he may require an appropriate reduction of the price or have the contract rescinded (the secondary remedies) (Article 5.5). The same holds true if the seller has not

guarantee, the consumer enjoys the benefits of the presumption. Other Member States (e.g. Belgium) took over the period of six months.

29. The European Court of Justice has interpreted the 'free of charge'-requirement very broad. For example, the seller cannot claim any usage fees for the normal use the consumer could have before the lack of conformity came into existence. Case 404/06, Quelle AG v. Bundesverband der Verbraucherzentralen und Verbraucherverbände, 2008 E.C.R. I-2713. Also, the consumer does not have to pay any costs of removal and new installation, if the consumer acted in good faith (i.e. before the lack of conformity was discovered) when installing the goods. However, according to the Court of Justice, nothing opposes to a national scheme allowing the consumer only to have a proportional part of the costs of replacement reimbursed. Joined Cases 65/09 \& 87/09, Gebr. Weber GmbH v. Jürgen Wittmer, Ingrid Putz v. Medianess Electronics GmbH, 2011 E.C.R. I-5295. 
completed the chosen primary remedy within a reasonable time, or if he has not completed it without significant inconvenience to the consumer. The dissolution of the contract will not be possible, however, if the lack of conformity is of minor importance, which is for the judge to decide. Consequently, also within the secondary remedies the consumer does not have complete freedom of choice.

\section{Application Problems of the Current Legislative Framework}

Regardless of the fact that the rules on consumer sales are a welcome addition to the armoury of the consumer in pursuance of a high degree of consumer protection, once again application problems are not far-fetched.

Evidently, the fact that digital content not supplied on a tangible medium completely falls outside of the scope of the Directive is a problem. This is especially true against the background of online distribution of digital content (streaming, downloading, etc.) gaining more and more importance. The consequences of this lack of applicability do not only concern digital content which was initially not supplied on a tangible medium (and thus ab initio fell outside of the scope of the rules on consumer sales), but also concern digital content which was initially supplied on a tangible medium (such as the digital content incorporated in goods with embedded software) which is later updated. Should this update be distributed online, which is very often the case, the question arises what the faith is of the goods with digital content incorporated therein. If as a consequence of the update the good is no longer in conformity with the contract, this lack of conformity was not present at the moment of delivery of the (initially materialised) digital content. Consequently, the seller's liability for the initially supplied good would not be endangered. If the consumer would argue that the lack of conformity is a consequence of the update, the seller could easily oppose that this update was distributed online and that as a consequence the 'new' digital content that was obtained via this update falls outside the material scope of application of the Consumer Sales Directive.

Another problem relates to the disparity between the period of two years during which the seller is basically liable on the one hand, and the presumption of anteriority which only covers six months from the day of delivery on the other hand. ${ }^{30}$ In our opinion, the fact that after the expiry of six months from the day of delivery the consumer would have to prove that the lack of conformity was already present at the moment of delivery, de facto often comes down to a limitation of the liability of the seller to six months, given the heavy burden of proof resting on the consumer's shoulders. This observation is even more true in the context of digital content, which is very often complex to such an extent that the consumer would need technical expertise investigations to establish the exact moment in which the lack of conformity came into existence. Given the price tag of such investigations, there are convincing reasons to fear that the consumer will decide not to try to prove that the lack of conformity was already present at the

30. It should be borne in mind, however, that the Member States can/could extend the presumption period, given the minimum harmonisation aimed at by the Directive. 
moment of supply. The outcome of a cost-benefit analysis between the expected costs of expert investigations on the one hand and the value of the goods on the other hand, taking into account the chances of success of proceedings, will from the viewpoint of the consumer be most likely negative. Moreover, a six-month period may be short in light of the nature of the good. As indicated above, consumers often 'discover' the goods; they do not always use all functionalities of a good from the start. If the consumer for example tries to play a CD on his computer after seven months and notices that this application does not work due to defective software, he will in principle not find redress in the Consumer Sales Directive. $^{31}$

Finally, the presumption of anteriority also conflicts with the idea of software being updated. If digital content which is supplied on a tangible medium (inter alia goods with embedded software) is updated within the first six months from delivery and is no longer in conformity due to this update, the consumer will be able to rely on the presumption of anteriority. The seller would then have to prove that the lack of conformity was not present at the moment of supply, which he will most likely be only able to do by proving that the lack of conformity is due to the update.

\section{A TWO-TRACK SYSTEM FOR DIGITAL CONTENT - (GOODS WITH) EMBEDDED SOFTWARE}

\section{A. Introduction - Level of Harmonisation}

The potential of online business, both purely domestic and cross-border, and the central position digital products have taken in our lives did not escape the attention of the Juncker-Commission. Even before he was actually installed, (future) Commission President Jean-Claude Juncker revealed his intentions to invest strongly in the creation of the 'Digital Single Market' (DSM). The realisation of the Digital Single Market would, according to him, generate an additional economic growth of 250 billion euros within the term of office of the current Commission. ${ }^{32}$ One of the points of focus was the adoption of new consumer protection legislation. Too often, sellers and consumers would relinquish doing business with one another because of the uncertainty surrounding the legal framework applicable to their relationships. This is all the more problematic if it concerns cross-border business. Given the minimum harmonisation provided for by the Consumer Sales Directive, which plays a central role in this whole story, both the seller and the consumer encounter legal uncertainty on the exact content of the applicable legislation. Moreover, if we

31. Note that others causes of action, such as liability for latent defects, may still prove to be useful. As indicated above, though, these remedies under general law of obligations are outside the scope of the current contribution.

32. Jean-Claude Juncker, Opening Speech in the European Parliament Plenary Session in Strasbourg: A New Start for Europe: My Agenda for Jobs, Growth, Fairness and Democratic Change, (July 15, 2014). 
assessed more specifically the context of digital content, it became clear that the existing provisions are often not adequate to react to the specific needs of consumers. Consequently, adaptations/additions to the existing legal framework were necessary.

On December 9, 2015, two proposals for Directives were presented: a proposal for a Directive on certain aspects concerning contracts for the supply of digital content on one side, ${ }^{33}$ and a proposal for a Directive on certain aspects concerning contracts for the online and other distance sales of goods on the other side. ${ }^{34}$ These would complement each other with regard to digital content. The former would apply to any digital content, including any durable medium incorporating digital content where the durable medium was used exclusively as a carrier of digital content, whilst the latter would apply to goods where digital content is embedded in such a way that its functions are subordinate to the main functionalities of the goods, and it operates as an integral part of the goods. ${ }^{35}$ The relationship between durable medium on one side and digital content on the other would thus decide which one of the Directives would be applicable.

The proposals have not been free of criticism, however. ${ }^{36}$ As a consequence, on October 31, 2017, the Commission launched an amended proposal for a directive on certain aspects concerning contracts for the sales of goods. ${ }^{37}$ This amended proposal foresaw in the applicability of the new rules to all contracts of sale concluded between a seller and a consumer. Nothing changed with regard to the (non) applicability to digital content or digital services. No amended proposal was brought forth for the proposed Digital Content Directive, though a wide range of changes were proposed in a joint report from the Committee on the Internal Market and Consumer Protection and the Committee on Legal Affairs. ${ }^{38}$ These included, inter alia, the application of the Digital Content Directive to embedded digital content or embedded digital services, but only insofar as the

33. See Proposal for a Directive of the European Parliament and of the Council of December 92015 on certain aspects concerning contracts for the supply of digital content, COM (2015) 287 final (Dec. 9, 2015).

34. See Proposal for a Directive of the European Parliament and of the Council of December 92015 on certain aspects concerning contracts for the online and other distance sales of goods, COM (2015) 288 final (Dec. 9, 2015).

35. Id. at 19 .

36. See for an elaborate overview the contributions of Sanne Jansen \& Sophie Stijns and Simon Geiregat \& Reinhard Steennot in Ignace Claeys \& Evelyne Terryn, Digital Content \& Distance Sales - New Developments at EU Level (2017).

37. Amended proposal for a Directive of the European Parliament and of the Council of October $31^{\text {th }} 2017$ on certain aspects concerning contracts for the sales of goods, amending Regulation (EC) No 2006/2004 of the European Parliament and of the Council and Directive 2009/22/EC of the European Parliament and of the Council and repealing Directive 1999/44/EC of the European Parliament and of the Council, COM (2017) 637 final (Oct. 31, 2017).

38. Report on the proposal for a directive of the European Parliament and of the Council on certain aspects concerning contracts for the supply of digital content, A8-0375/2017 (November 27, 2017). 
digital content or services were pre-installed (Article 2.1 (1b) in conjunction with 3.3 of the amended proposal). Given the fact that the Proposed Goods Directive would still apply to everything concerning goods with embedded digital content or embedded digital services irrespective of pre-installation or not, the scopes of applications of the two amended proposals would consequently overlap.

Apparently aware of the fact that the 'split approach' as proposed by the parliamentary committees would only enhance legal uncertainty, the Council indicated in a policy note of May 24, 2018 that it intended to maintain the original idea to bring goods with embedded digital content completely under the scope of application of the Goods Directive. ${ }^{39}$ It held that one good with embedded software could entail the applicability of two different sets of rules, depending on whether the liability would flow from the hardware or from the digital content. Fierce and long lasting discussions would then be unavoidable concerning the question what exactly caused the defect. If both components are subject to the same system, these discussions would be unnecessary. On the other hand, the Council acknowledged that in the context of the Goods Directive attention had to be paid to the role of digital services. If these have the same function as embedded digital content, and/or are equally closely linked to the functioning of the good, these services should be covered by the goods rules in the same way as embedded digital content. ${ }^{40}$ Consequently, the substance of the proposal was modified one last time on December 3, 2018 in the hope of establishing a balanced compromise between the positions expressed by the different delegations from the Member States. ${ }^{41}$ Finally, both directives were adopted on May 20, 2019 and published on May 22, 2019. The implementation in the national legislation of the Member States has to take place by July 1, 2021 (Article 24). The final versions hold on to the original two-track system, depending on whether or not the durable medium's only function was to carry the digital content. ${ }^{42}$

Both the Digital Content Directive and the Goods Directive aim at maximum harmonisation (Article 4 DCD, Article 4 GD). By doing so, the European legislator wants to do away with the negative consequences of the minimum harmonisation aimed at by the CSD, and the diverging national approaches. ${ }^{43}$

39. Policy Note (EC) No. 9261/18 of May 24, 2018, 4-5.

40. Id. at 5 .

41. Supra note 37.

42. See Directive 2019/771, of the European Parliament and of the Council of 20 May 2019 on certain aspects concerning contracts for the sale of goods, amending Regulation 2017/2394 and Directive 2009/22/EC, and repealing Directive 1999/44/EC, 2019 O.J. (L 106) (consultable via https://eur-lex.europa.eu/legal-content/en/TXT/?uri=CELEX:32019L0771 [perma.cc/36VVYMCV]) [hereinafter Goods Directive]; Directive 2019/790, of the European Parliament and of the Council of 17 April 2019 on copyright and related rights in the Digital Single Market and amending Directives 96/9/EC and 2001/29/EC, 2019 O.J. (L 130) (consultable via https://eurlex.europa.eu/legal-content/EN/TXT/?uri=CELEX\%3A32019L0790 [perma.cc/722T-FBDY]) [hereinafter Digital Content Directive].

43. Goods Directive, supra note 45 at 29. 
Both proposals are very similar to each other, although on some points diverging rules have been enacted due to the broader scope of application of the Goods Directive in comparison to the Digital Content Directive. For the remaining of this contribution, we will focus on the Goods Directive, more specifically in the context of goods with embedded digital content/digital services.

\section{B. Digital Content and Digital Services - Goods with Embedded Software}

The Goods Directive uses the same concept of 'digital content' as the Digital Content Directive, based on the Consumer Sales Directive. Digital content means data which are produced and supplied in digital form (Article 2 (6) GD). Digital content entails, for example, software programs, games, video and audio records, etc. New for the Goods Directive is the introduction of 'digital services.' These are described in a very similar way as is the case for the Digital Content Directive. A digital service is (i) a service that allows the consumer to create, process, store or access data in digital form or (ii) a service that allows the sharing of or any interaction with data in digital form uploaded or created by the consumer or other users of that service (Article 2 (7) GD). Examples include social media platforms (Facebook, Twitter, etc.), cloud services, etc.

Though the term 'embedded software' has already been used multiple times before, we did not yet describe exactly what it is, nor what exactly goods with embedded software are. The reason is that these concepts were up until now legally irrelevant. No legal consequences were attached to whether or not something was (a good with) embedded software. In the near future, however, this will change. More specifically for goods with digital content, a division will be made between 'goods with digital elements' on the one hand, and digital content of which the durable medium has no other function than medium of the digital content, on the other hand. The Goods Directive gives no definition of 'goods with embedded software'. 'Goods with digital elements,' however, are defined as all tangible movable items that incorporate or are inter-connected with digital content or a digital service in such a way that the absence of that digital content or digital service would prevent the goods from performing their functions (Article 2 (5) GD).$^{44}$ Both digital content which was already installed at the moment of conclusion of the contract and digital content of which the installation is foreseen in the contract fall under the scope of application. Digital services inter-connected with a good may include services that allow the creation, processing or storage of data in digital form, or access thereto, such as the continuous supply of traffic data in a GPS-system. ${ }^{45}$

As mentioned above, goods with digital content/digital services cannot be seen as goods with digital elements in the sense of the Goods Directive if the

44. Goods Directive, supra note 45 at 30 , which states that "[d]igital content that is incorporated in or inter-connected with a good can be any data which is produced and supplied in digital form, such as operating systems, applications and any other software", makes us presume that 'goods with embedded software' and 'goods with digital element' are synonyms.

45. Id. 
good solely functions as medium of the digital content or digital service (Article 3.3 Goods Directive). Examples include CDs or USB flash drives on which a software program is supplied. In case of a defect which only concerns the tangible medium (e.g. the CD is scratched and as a consequence the software-with which nothing is wrong-cannot be installed), we are of the opinion that the consumer will have to fall back on the Goods Directive. Surely, the CD which functions solely as a medium for the digital content is not a good with digital elements, though the $\mathrm{CD}$ on its own is still a tangible movable item, and therefore a good in the sense of the Goods Directive (Article 2 (5) (a) GD).

\section{Lack of Conformity of Goods with Digital Elements}

\section{Conformity of Goods: General}

According to Article $5 \mathrm{GD}$, the seller has to deliver goods to the consumer that, depending on the circumstances, meet subjective and objective conformity requirements. The distinction between these two types of conformity requirements is also applied in the Digital Content Directive. Following the criticism made in the context of the Digital Content Directive, which initially held that the objective criteria would only come into play if the subjective criteria were not stipulated in a clear and comprehensive manner (see Article 6 of the original proposal of the DCD) ${ }^{46}$ the Goods Directive foresees the $a b$ initio mutual application of both the subjective and objective conformity requirements. Moreover, the seller has to make sure under certain circumstances that the installation is properly conducted and that the rights of third-parties do not limit or prevent the use of the goods.

\section{Subjective Conformity Requirements}

The subjective conformity requirements are the ones parties agreed on at the moment of conclusion of the contract, as a consequence of which the seller is bound (pacta sunt servanda). More precisely the goods have to be (i) of the description, type, quantity, and quality, and possess the functionality, compatibility, interoperability and other features, as required by the contract, (ii) fit for any particular purpose for which the consumer requires them and which he made known to the seller at the latest at the time of conclusion of the contract, and in respect of which the seller has given acceptance, (iii) delivered with all accessories and instruction, including on installation, as stipulated by the sales contract, and (iv) supplied with updates as the contract stipulates (Article 6 GD). In pursuance of the Digital Content Directive, the European legislator clarified that the pre-contractual information forms an integral part of the contract for the application of the Goods Directive as well, as a consequence of which they have

46. Simon Geiregat \& Reinhard Steennot, Proposal for a Directive on Digital ContentScope of Application and Liability for a Lack of Conformity, in IGNACE ClAEYS \& EvelynE TERRYN, supra note 39, at 121. 
to be taken into account in order to determine whether or not the good is in conformity. ${ }^{47}$

\section{Objective Conformity Requirements}

Next to the conformity requirements as stipulated in the contract, the Goods Directive provides objective requirements which have to be fulfilled (Article 7 GD). The goods have to be (i) fit for the purposes for which goods of the same type would normally be used, taking into account, where applicable, technical standards or applicable sector-specific codes of conduct and (ii) of the quantity and possess the qualities and other features, including in relation to durability, functionality, compatibility and security normal for goods of the same type and which the consumer may reasonably expect, given the nature of the goods and taking into account any public statements made by or on behalf of the seller or other persons in previous links of the chain of transactions, including the producer, particularly in advertising or on labelling. Where applicable, the goods have to be (iii) of the quality and correspond to the description of a sample or model that the seller made available to the consumer before the conclusion of the contract and (iv) delivered along with such accessories, including packaging, installation instructions or other instructions, as the consumer may reasonably expect.

In pursuance of the Consumer Sales Directive, the Goods Directive states that the seller is not bound by public statements if he proves that (i) he was not, and could not reasonably have been aware of the public statement in question, (ii) by the time of conclusion of the contract, the public statement had been corrected in the same way as, or in a way comparable to how it had been made, or (iii) the decision to buy the goods could not have been influenced by the abovementioned public statement (Article 7.2 GD). Moreover, there is no lack of conformity if at the time of the conclusion of the contract, the consumer was specifically informed that a particular characteristic of the goods was deviating from the objective requirements for conformity and he expressly and separately accepted that deviation when concluding the sales contract (Article 7.5 GD). The exception which existed under the Consumer Sales Directive according to which there would be no lack of conformity if the latter had its origin in materials supplied by the consumer is not maintained in the new Goods Directive.

Entirely new is the developed framework concerning the objective conformity requirements of goods with digital elements. ${ }^{48}$ Next to the abovementioned objective conformity requirements, the Goods Directive entails the seller's duty to ensure that the consumer is informed of and supplied with updates, including security updates, that are necessary to keep the goods in

47. Goods Directive, supra note 45 at Recital 26.

48. This framework was still absent in the modified proposal of the Goods Directive. The latter only provided that the seller had to make sure that "in the case of goods with digital elements [these are] updated, including [. . .] security updates, as necessary to maintain conformity[.]" See Article 5.1 (b2) of this modified proposal. 
conformity. For contracts including a single act of supply of the digital content or digital service, this duty applies for the period that the consumer may reasonably expect, given the type and purpose of the goods and the digital elements and taking into account the circumstances and nature of the contract. In the case of contracts that include a continuous supply of the digital content or digital service, the duty applies for a period of two years starting from the moment the goods with digital elements were delivered. Should the period during which the digital content or digital service has to be supplied be longer than two years (according to the contract), the duty for the seller to notify and supply updates applies for the entire period during which he has to supply the digital content or digital service (Article 7.3 GD, under reference to Article 10.2 GD). In the event the consumer fails to install the updates supplied by the seller within a reasonable time, the seller cannot be held liable for any lack of conformity resulting solely from the lack of the relevant update. This is only true however in as far as (i) the seller informed the consumer about the availability of the update and the consequences of failure of the consumer to install it and (ii) the failure to install or the incorrect installation by the consumer was not due to shortcomings in the installation instructions provided to the consumer (Article 7.4 GD).

\section{Considerations Concerning the Conformity Requirements}

It is obvious from the explicit references to updates that the European legislator is aware of the deficiencies of the Consumer Sales Directive in the context of updates/updated goods. More precisely, the Goods Directive now entails the duty for the seller to update goods with digital elements in as far as this is necessary to keep the goods in conformity, even after the moment of delivery. If not, these goods are not conforming, and as a consequence, the seller may be held liable.

Some remarks can be made concerning this new legal framework, however. First of all, a tautology may be found in the description of the objective conformity criteria. Goods with digital elements have to be updated, including safety updates, in order to keep them conforming. Consequently, the 'global concept' is filled in under references to the idea of conformity itself. Evidently, the conformity that has to be maintained by means of updates has to be filled in by means of the other subjective and objective conformity requirements.

Next, it is apparent from the wording of the Goods Directive that the duty to notify and supply updates rests on the seller's shoulders (Article 7.3 GD). Should the good no longer be in conformity due to this update, though, only the seller is held liable by the Goods Directive. It follows from the recitals, however, that the updates can be provided by the seller or by a third party. ${ }^{49}$ The Directive foresees a right of redress for the seller, which is determined by the national law of the Member States (Article 18 GD). Though it does not directly concern the consumer, the question arises as to what extent this right of redress will turn out to be useful in practice in the context of goods with digital elements. If, for

49. Council Directive 2019/771, 2019 O.J. (L 136) 28, 33 (EU). 
example, the local electronics store sells a smartphone (e.g. iPhone) on which software is pre-installed and, due to a software-update supplied by Apple, the device is no longer conforming, the consumer would have the possibility to file liability claims based on the Goods Directive against the local seller. Subsequently, the latter theoretically has the right to claim redress from Apple. However, given the unequal playing field on which the local seller and Apple operate, it may be questioned whether this attempt would be fruitful. This could in turn trigger the local seller to stop distributing certain goods or certain brands, in order to avoid such tenuous situations. ${ }^{50}$ The consumer might thus indirectly experience negative consequences, although it should be noted that commercial considerations will probably convince the seller to continue distributing a certain good or brand. Another point is that the right of redress is limited to redress against persons in previous links of the chain of transactions. ${ }^{51}$ It cannot be excluded, however, that the third party supplying the updates is not a 'previous link' of the chain of transactions. If a sales contract provides that the digital content or digital service will be provided by a trading partner of the seller after delivery of the physical component, it is, in our opinion, still unclear whether or not this third party can be considered a 'previous link'. Consequently, application problems are not far fetched.

Another aspect concerns the period of time during which the seller has to notify and supply updates. As indicated above, the Goods Directive provides in the context of sales contract which foresee in a single act of supply that the seller has this duty 'during the period that the consumer may reasonably expect'. This wording is much vaguer than the one for contracts foreseeing a continuous supply of digital content or digital service, where the duty exists for at least two years (and potentially longer, in the case of contracts foreseeing a continuous supply for a period of more than two years). However, given the fact that updates are necessary to keep the good in conformity and are taken into account when determining conformity itself, it would logically be suitable to align the period of notification and supply of updates in the context of contracts entailing one single act of supply with the period during which the seller can be held liable for a lack of conformity (i.e. two years).

Finally, there seem to be (unjustified) inconsistencies between the Goods Directive and the Digital Content Directive. Whereas the latter refers to qualities and performance features such as accessibility, continuity and security of digital content or digital service for the conformity assessment (Article 8.1 (b) DCD), a similar reference is lacking in the Goods Directive. Whereas security is still mentioned (Article 7.1 (d) GD), every reference to accessibility and continuity

50. Moreover, it exemplifies the necessity to consider the desirability of European harmonisation of provisions that impose rights on certain undertakings which are similar to the ones consumers derive from consumer protection law initiatives. It should be noted, however, that attempts to this end have already been taken. In Belgium, for example, there is a proposition pending in Parliament concerning unfair contract terms and unfair commercial practices between undertakings. Legislative proposal of $22^{\text {nd }}$ February 2019, nr. 54-3595/001.

51. Council Directive 2019/771, 2019 O.J. (L 136) 28, 38 (EU). 
is absent. Although these aspects can without any doubt be brought under the umbrella of 'other features' (Article 7.1 (d) GD), it would be preferable to explicitly refer to them in the relevant legal provisions. This would a priori have excluded every a contrario reasoning in that regard.

\section{Incorrect Installation and Third-party Rights}

In pursuance to the Consumer Sales Directive, the Goods Directive holds provisions for goods needing to be installed. In as far as the lack of conformity results from an incorrect installation, the seller is liable if the installation (i) forms part of the contract of sale and was carried out by the seller or under the latter's responsibility or (ii) was intended to be carried out by the consumer, was done by the consumer or under his supervision, ${ }^{52}$ and the incorrect installation was due to shortcomings in the installation instructions provided by the seller or, in the case of goods with digital elements, by the supplier of the digital content or digital service (Article $8 \mathrm{GD}$ ). One can, for example, think of the delivery of a kitchen robot, on which the software still has to be installed by means of a CD which is supplied along with the device itself. This contract would fall under the scope of application of the Goods Directive (Article 3.3 GD). Should, as a consequence of a shortcoming in the installation instructions, the digital content be wrongfully installed due to which the kitchen robot is no longer conforming (e.g. it explodes), there will be a lack of conformity. However, if one looks at the two separate elements - the physical component and the digital content - one might conclude that in se nothing was wrong with both of them.

Last, a lack of conformity might also arise from third-party rights. If a restriction resulting from a violation of any right of a third party, in particular intellectual property rights, prevents or limits the use of the goods in accordance with the abovementioned subjective and objective conformity requirements, the consumer has to be entitled to the remedies provided for by the Directive (Article 9 GD). This is only different in as far as national law of the Member State provides for the nullity or rescission of the sales contract in such circumstances.

\section{Liability of the Seller-Remedies}

\section{Liability}

The seller is liable to the consumer for any lack of conformity which exists at the time the goods were delivered (Article 10.1 GD). This is also the case for goods with digital elements, without prejudice to the particular rules concerning updates.

Different rules apply in relation to goods with digital elements when the agreement stipulates a continuous supply of the digital content or digital service

52. This does not follow from the wording of Article 8, though is apparent from recital 34. Council Directive 2019/771, 2019 O.J. (L136) 28, 34 (EU). 
over a period of time. ${ }^{53}$ The seller shall then also be liable for any lack of conformity of the digital content or digital service that occurs or becomes apparent within two years from the time of delivery of the goods containing digital elements, unless the contract provides for a continuous supply of more than two years. In the latter situation, the seller is liable for any lack of conformity which occurs or becomes apparent within the period of time during which the digital content or digital service is to be supplied under the sales contract (Article 10.2 GD). The new directive ensures that the seller cannot be obligated to deliver digital content or digital services during a period of time in which he can no longer be held liable for desisting from such delivery. Member States may maintain or introduce longer time limits than those referred to (Article 10.3 GD). It remains doubtful, however, whether they will effectively use this opportunity, considering most Member States merely literally copied the time limits of the Consumer Sales Directive. ${ }^{54}$

It is again obvious that particular attention was given to goods with digital elements. The content of the discussed provisions remains suboptimal, in the sense that it seems unclear what can be precisely understood under the phrasing 'delivery of goods with digital elements'. One could mistakenly suspect that the delivery of the physical component suffices. However, the time when physical delivery was the end of it is behind us and from the recitals, it seems goods with digital elements are considered 'delivered' when both the physical and digital components are delivered. In a situation of continuous supply, the good with digital elements is considered delivered when delivery has begun, i.e. the moment of the first delivery ${ }^{55}$ In a situation where goods with digital elements have to be installed by the seller or under his responsibility, they are considered delivered when the installation has been completed. ${ }^{56}$

No different than the Consumer Sales Directive, the new Goods Directive provides for a time limit of seller liability of two years during which the lack of conformity becomes apparent since the delivery (Article 10.1 GD). In other words, the lack of conformity must manifest itself (and thus not arise! $!^{57}$ ) within two years after delivery. When the consumer can prove the lack of conformity already existed at the time of the delivery but only appeared after those two years, he will not be able to invoke the rules of the Goods Directive. ${ }^{58}$ In the case of second-hand goods, the existing arrangement has also been copied: the consumer and the seller can agree on shorter time limits, provided that such shorter periods

53. Agreements concerning goods with digital elements which provide for a one-time delivery are subject to the general rule (i.e. liability of the seller during the first two years after delivery).

54. Communication from the Commission to the Council and the European Parliament 8, COM (2007) 210 final (Apr. 24, 2007).

55. Council Directive 2019/771, 2019 O.J. (L 136) 28, 34-35 (EU).

56. Council Directive 2019/771, 2019 O.J. (L136) 28, 35 (EU).

57. The lack of conformity has to be present at the moment of delivery.

58. As indicated above, non-consumer law ways of action are still possible but remain outside the scope of the current contribution however. 
shall not be less than one year (Article 10.6 GD).

In relation to goods with digital elements, the seller is liable for every lack of conformity of the digital content or the digital service which would become apparent during the above mentioned time limits, depending on whether the delivery occurred once or was continuous (Article 10.1 GD). Thus, when an update is carried out after the first two years upon delivery which causes the good to lack conformity, the consumer is let down, since this would constitute a lack of conformity which (per definition) manifested itself two years after the delivery of the good. ${ }^{59}$ This can turn out to be especially problematic in relation to goods that the consumer seldom uses.

It is important to emphasize that the new legal framework concerning continuous supply of digital content or elements overlooks reality. It holds true that many goods, and also many goods with digital elements, remain unchanged after delivery of this good. This was also the angle of the Consumer Sales Directive. Where appropriate, the time limit of liability comes down to a 'critical time limit' during which a lack of conformity has time to manifest itself. When this lack of conformity manifests itself shortly after the delivery, then it is presumed to have been already present at the moment of delivery.$^{60}$ If it occurred later, but still within two years, then the consumer could still prove the good was delivered lacking conformity with the contract of sale. Yet, when the lack of conformity manifested itself after the time limit of liability, then the consumer can no longer invoke the favourable regime. This declining regime of protection can be considered obvious to some extent since the probability of a lack of conformity which was present at the time of delivery diminishes as time flows. This way of thinking is based upon the assumption that the seller has completed all his legal obligations (i.e. concerning delivery in conformity) at that moment. With goods with digital elements where the agreement provides for continuous supply, it is a different ballgame. As mentioned earlier, the lack of conformity can manifest itself after the goods were delivered (i.e. both the physical component as well as the (first) delivery of the digital content or service). This means the critical time limit has already commenced when the lack of conformity still has to arise. Delivery of digital content or digital services based upon the agreement are literally still possible up until minutes before the expiration of the time limit of liability and these can still give rise to a lack of conformity. By no means is it excluded that something goes wrong in the sense that (fraudulent?) sellers or third parties (i.e. producers) by delivering digital content or services, cause the good to lack conformity just moments before the passing of the time limit. The consumer will then have to react immediately, be it that this theory assumes that the consumer can actually also identify the lack of conformity within the short remainder of the critical time limit. If digital content were to be installed just fifteen minutes before the passing of the time limit and only the next day results in a lack of conformity of the good, then the consumer will be left out in the

59. Note that the period can be longer for contracts of sale providing for a continuous supply for a period longer than two years.

60. See above Section 5 with regard to the presumption of anteriority. 
cold $^{61}$, even though there is a lack of conformity which manifests itself within a short period after the good became non-conformant.

An example can shed light upon the previous. A consumer buys a smart TV on January $1^{\text {st }} 2020$. The agreement dictates that during five years the most recent version of the software will be continuously delivered. The consumer receives the good with the software (i.e. digital content) already installed and thus the good with digital elements can be considered delivered on that very same day. All goes well in the coming years but on December $31^{\text {st }} 2024,11: 30$ PM, the latest version of digital content is delivered, causing the good to be no longer in conformity with the contract of sale (e.g. the device can no longer boot). The consumer enjoys New Year's Eve with his friends and spends all of New Year's Day with his family. Exhausted on January $2^{\text {nd }}$, he wants to turn on the device but notices the television does not work. Since the good was considered delivered on January $1^{\text {st }} 2020$ and as such the critical time limit of five years ${ }^{62}$ expired on January $1^{\text {st }}$ 2025 , the consumer will no longer be able to invoke the favourable rules for a lack of conformity if this manifests itself on January $2^{\text {nd }} 2025$. When this case is regarded from the perspective of the lack of conformity, this only manifested itself less than two days after it was created. This seems unfair for a consumer who can now no longer invoke the favourable rules of the new directive.

In our opinion, the legislative defect flows from the absolute and sole starting point of the 'critical time limit'. In relation to goods with digital elements of which the agreement provides for a continuous supply of digital content or digital services, 'the delivery' is indeed defined as the moment when both the physical component is delivered as well as the digital component is delivered for the first time. Hence, a better option would have been the establishment of an additional and variable starting point for a, possibly shorter, critical period from each new delivery of digital content or digital services (i.e. a critical period with variable starting point).

The above mentioned presumption of anteriority has been extended until one year (instead of six months). Any lack of conformity which becomes apparent within one year of the time when the goods were delivered shall be presumed to have existed at the time when the goods were delivered, unless proved otherwise or unless this presumption is incompatible with the nature of the goods or with the nature of the lack of conformity (Article 11.1 GD). The directive, however, also gives the opportunity to Member States to maintain or introduce a period of two years instead of one year (Article 11.2 GD). Even though a strict interpretation of the text of this second provision leads to the conclusion that Member States cannot introduce or maintain other periods than either one or two years, the adage qui peut le plus, peut le moins ("he who can do more, can do less") contends that Member States can introduce or maintain periods in between

61. Apart from the means of action under general law.

62. See Council Directive 2019/771, art. 10, 2019 O.J. (L 136) 28, 43 (EU). The liability period is extended to five years, given the fact that Article $10 \mathrm{GD}$ provides that in each case where the contract stipulates the continuous supply for a period of more than two years, the consumer can rely on the remedies provided for in the Goods Directive during that same period. $I d$. 
one and two years.

In relation to goods with digital elements, both those where the agreement provides for a continuous supply and those where it does not, the Proposition of the Goods Directive was more generous. More specifically, it immediately constituted a presumption of anteriority (and thus a reversed burden of proof) during the whole period in which the seller could be held liable (Article 8ter, 2). This stood in contrast to goods without digital elements, where the 'default rule' stated that there is a presumption of anteriority only during half of the period of liability (i.e. the current rule: one year). It can be considered appropriate from the perspective of consumer protection in relation to goods with digital elements if the period of a reversed burden of proof and the period of liability coincided.

The Goods Directive in its final version, however, stipulates that for contracts prescribing a single act of supply of digital content or services, only a one year period of reversed burden of proof will apply (Article 11.1 GD). Member States may, however, extend this period to two years. This adaptation is regrettable. First of all, the system, as enacted in the proposition (i.e. reversed burden of proof during two years upon delivery), would have met the above mentioned criticism in relation to goods with digital elements. The disparity between the period of presumed anteriority and the period of liability in fact leads to only a guarantee for the consumer when the burden of proof is reversed. Even though the directive expressly provides for a possibility for Member States to equalise both periods, the past has shown that not all Member States are inclined to do so. After all, the minimal harmonisation nature of the previous Consumer Sales Directive did not prevent Member States from synchronisingthe period of a reversed burden of proof and the period of liability. If we look at the implementation of the previous directive in the Member States, it is apparent that not all Member States used this opportunity. ${ }^{63}$ Consequently, it is hard to imagine that they would all suddenly do the opposite.

In relation to contracts prescribing a continuous supply, the final version of the Directive has it that the reversed burden of proof applies for a period of two years upon delivery (delivery of the physical and (first) delivery of the digital component), unless the contract foresees a period of more than two years during which digital content or services have to be supplied. In the latter event, the burden of proof is reversed during the same amount of time as the one during which digital content or services have to be supplied continuously. Consequently, it is argued that with regard to contracts prescribing a continuous supply, the Goods Directive is more consumer friendly and 'reality-proof' than it is in relation to contracts holding a single act of supply.

In accordance with Article 12, they can provide that the consumer must notify the seller "within a period of at least 2 months of the date on which the consumer detected such lack of conformity". Again, the phrasing leaves much to be desired. Based on the words of the provision it seems that the period may be shorter than

63. Belgium, for example, did not extend the period of the presumption of anteriority. France on the other hand did. 
two months. The provision would then have no additional value since nothing ${ }^{64}$ hinders Member States from maintaining or introducing shorter periods, in which they could again envisage a longer period based upon the adage qui peut le plus, peut le moins. Additionally, the recitals show that the phrasing is wrong. It reads that Member States should be allowed to establish the obligation for the consumer to inform the seller "within a period not shorter than two months" from the date on which the consumer detected such lack of conformity. ${ }^{65}$ Given the use of "not shorter than", nothing prevents the establishment of a longer period. The new directive thus seamlessly follows the previous one. ${ }^{66}$

\section{Remedies}

In accordance with the Consumer Sales Directive, the new Goods Directive provides for four remedies. It concerns repair or replacement free of charge, a proportionate reduction in the price or termination of contract (Article 13.1 Goods Directive). It should be made clear that the first two of these remedies are aiming at restoring the lack of conformity with the contract of sale and thus strive for a redress in kind, whilst the last two remedies rather entail redress by equivalence. Similar to the previous directive, the consumer can also attempt to receive damages. ${ }^{67}$

Apart from the remedies, the hierarchy has also been maintained, be it that the Goods Directive elaborates more closely on the criteria which must or may be fulfilled before one or the other remedy can or cannot be requested. When the goods do not seem in conformity, then the consumer can first choose between repair or replacement, both of which are free of charge. In principle, the consumer has freedom of choice between both remedies, unless the remedy chosen would be impossible or, compared to the other remedy, would impose costs on the seller that would be disproportionate (Article 13.2 Goods Directive).$^{68}$ In addition, the directive expressly provides the seller the right to refuse to bring the goods into conformity if repair or replacement are impossible or would impose costs on the

64. See Council Directive 2019/771, art. 10, 2019 O.J. (L 136) 28, 43 (EU). The literal wording of Article 12 GD provides that Member States may maintain or introduce such a period. Nothing obligates them to do so. Id.

65. Council Directive 2019/771, 2019 O.J. (L 136) 28, 36 (EU).

66. See Case C-497/13, Froukje Faber v. Autobedrijf Hazet Ochten BV, 2015 E.C.L.I. 357 (ruling that the notification to be given relates only to the existence of the lack of conformity and that it is not subject to rules of evidence which would make it impossible or excessively difficult for the consumer to exercise his rights).

67. See Council Directive 2019/771, 2019 O.J. (L 136) 28, 31, 37 (EU).

68. The latter requires that all circumstances are taken into account, including (a) the value the goods would have if there were no lack of conformity, (b) the significance of the lack of conformity and (c) whether the alternative remedy could be provided without significant inconvenience to the consumer. For instance, it might be disproportionate to request the replacement of the good because of a minor scratch See Council Directive 2019/771, 2019 O.J. (L 136) 28,36 (EU). 
seller that would be disproportionate (Article 13.3 Goods Directive). When both repair or replacement cannot be completed, are not in accordance with the legal conditions, or when the seller has refused to bring the goods into conformity, then the consumer has a right to a proportionate reduction of the price or to terminate the agreement (Article 13.4 Goods Directive). This right to the secondary remedies also applies when the lack of conformity persists despite the seller's attempt to bring the goods into conformity. ${ }^{69}$ Also when the lack of conformity is of such a serious nature as to justify an immediate price reduction or termination of the sales contract, or when the seller has declared, or it is clear from the circumstances, that the seller will not bring the goods into conformity within a reasonable time, or without significant inconvenience for the consumer, the secondary are at the consumers disposal. In principle the consumer then has freedom of choice between a proportionate reduction of the price or the termination of the agreement, except when the lack of conformity is only of minor importance (Article 13.5. Goods Directive). Termination of contract is, in the latter case, not permitted. These abstract concepts (minor importance, reasonable time, significant inconvenience) grant a wide margin of discretion to the judge. Nevertheless, this was also the case in the Consumer Sales Directive and therefore inspiration can be drawn from the case law which was then developed.

New is the legal base for the so-called 'exceptio non adimpleti contractus ${ }^{70}$. The consumer then has the right to withhold payment of any outstanding part of the price or a part thereof until the seller has fulfilled the seller's obligations under the directive (Article 13.6 Goods Directive). Finally, the new directive stipulates that Member States may regulate whether and to what extent a contribution of the consumer to the lack of conformity affects the consumer's right to remedies.

The content of the provisions containing the remedies clearly shows that the new directive more or less copy-pasted its predecessor. Consequently, case law regarding the latter can be transposed insofar as this is useful. For example, case law concerning the possibility for the consumer to modify the original claim where no reduction of price was demanded to that end, in case he asked for termination, but this was refused because the lack of conformity was only of minor importance. ${ }^{71}$

As previously mentioned, the first option for the consumer is to restore the lack of conformity with the contract of sale, notably by repairing or replacing the good (Article 14 Goods Directive). Enabling consumers to require repair should, according to the recitals, encourage sustainable consumption and could contribute

69. In our opinion, this could mean both a lack of conformity which manifests itself again shortly afterwards or which continuous to manifest itself.

70. In the circumstance of a reciprocal contract (e.g. an agreement of sales), this remedy of defence allows one party to suspend his or her contractual obligations when and after the other party defaults on his or her respectively.

71. Case C-32/12, Soledad Duarte Hueros v. Autociba SA, Automóviles Citroën España SA, 2013 E.C.L.I 637. 
to greater durability of products. ${ }^{72}$ From the perspective of durability this consequently leads to a preference of repair over replacement.

Repair or replacement shall be carried out free of charge. This means, inter alia, that the consumer should not have to pay for the normal use in the period which precedes the replacement and that the seller should take back the replaceable goods at his expense. Additionally, this has to be carried out within a reasonable period of time from the moment the seller has been informed by the consumer of the lack of conformity and without any significant inconvenience to the consumer, taking into account the nature of the goods and the purpose for which the consumer required the goods. In turn, the consumer has to make the goods available to the seller so that the latter has the opportunity to carry out repair or replacement. Insofar it concerns goods that have to be installed, the obligation to repair or replace also entails the obligation of the removal of the non-conforming goods, or to bear the costs thereof.

When, due to one of the above-mentioned reasons, redress in kind is out of the question, the consumer can still choose between the proportionate reduction of price, on the one hand, or termination of contract, on the other.

Concerning the reduction of price, the new directive states that this shall be in proportion to the decrease in value of the goods which were received by the consumer compared with the value that the goods would have had if they were in conformity (Article 15 Goods Directive). Once again, this concerns a transposition of that which already existed under the Consumer Sales Directive.

The 'ultimum remedium' of the new directive is however, again in accordance with the Consumer Sales Directive, the termination of contract. The consumer shall exercise this right by means of a statement to the seller expressing the decision to terminate the sales contract (Article 16.1 Goods Directive). Since no particular rules of evidence are specified, the consumer must, by himself, evaluate whether he possesses sufficient evidence. The main consequences of the termination are by contrast specified in the new directive: the seller has to reimburse the consumer the price paid for the goods upon receipt of the goods or of evidence provided by the consumer of having sent back the goods whilst the consumer has to return to the seller, at the seller's expense, the goods (Article 16.3 Goods Directive). In respect to other consequences, the choice remains with the Member States, for example concerning the consequences of decrease in value, destruction or loss of the good. ${ }^{73}$

A novelty in the directive is the possibility of a 'partial termination'. Where the lack of conformity relates to only some of the goods delivered under the sales contract and there is a ground for termination of the sales contract pursuant to Article 13, the consumer may terminate the sales contract only in relation to those goods, and in relation to any other goods which the consumer has acquired together with the non-conforming goods if the consumer cannot reasonably be

72. See Council Directive 2019/771, 2019 O.J. (L 136) 28, 36 (EU).

73. Council Directive 2019/771, 2019 O.J. (L 136) 28, 37 (EU). Article 16.3 GD refers to the modalities for return and reimbursement. Council Directive 2019/771, art. 16.3, 2019 O.J. (L 136) $28,45(\mathrm{EU})$. 
expected to keep only the conforming goods (Article 16.2 Goods Directive). The purchase of a laptop can serve as an example. When the laptop appears to lack conformity but the charger does not, then the consumer cannot be expected to keep this charger.

The Goods Directive copied the Consumer Sales Directive to a great extent. Even though this is understandable since the former will replace the latter (and thus will apply to 'normal' goods), the lack of particular attention to goods with digital elements is remarkable. Where the new directive pays much attention to the specificities of goods with digital elements in respect to seller liability, not one word is mentioned in the domain of remedies. In view of remedies being the big stick of the directive, this can be regarded as a scourge.

The drafters of the new Goods Directive could have found useful inspiration in the Digital Content Directive. Without further elaboration on the latter, we want to point out, for example, the possibility for the consumer to oblige the trader to make available any content other than personal data, which was provided or created by the consumer when using the digital content or digital service supplied by the trader (Article 16.4 in conjunction with 16.5 Digital Content Directive). In respect of cloud services, this could mean that the movement of data from a cloud to a new location when this is no longer available in consequence of termination of contract. Such a possibility would also have been welcome in the new Goods Directive. When, as a consequence of the termination, the agreement is immediately ended, the risk exists that the consumer no longer has access to certain content (e.g. photos and documents) that he saved in a cloud service (e.g. iCloud) which can only be accessed through certain goods (e.g. Apple products). Also, the extensive arrangements in the Digital Content Directive on how a trader should act after termination (Articles 16 until 18) and in regard to the modification of digital content or services (Article 19) could, to some extent, have been adopted in the Goods Directive since digital content or digital services that are embedded in goods do not differ in essence from digital content or digital goods which is traded separately (i.e. not embedded).

\section{ENFORCEMENT OF INFRINGEMENTS CONCERNING GOODS WITH EMBEDDED SOFTWARE}

\section{A. The Dieselgate Scandal: Facts of a Large-scale Infringement Concerning Embedded Software}

This fourth part addresses the enforcement of infringements on the subject of goods with embedded software. To do so, the assessment will refer to the socalled 'Dieselgate scandal' to identify certain challenges for enforcement which flow thereof. It was discovered in September $2015^{74}$ that about 11 million diesel

74. See Notice of Violation from Phillip A. Brooks, Director, Air Enforcement Division, Office of Civil Enforcement, United States Environmental Protection Agency, to David Geanacopoulos, Executive Vice President Public Affairs and General Counsel, Volkswagen Group of America, Inc. (Sep. 18, 2015), https://www.epa.gov/sites/production/files/2015- 
fuelled cars of the Volkswagen AG group, 8 million of which had been retailed in the European Union, were equipped with fraudulently embedded software. It was fraudulent because the programming was purposely meant to bypass diesel emission standards by activating certain emission control systems only during laboratory testing (i.e. 'defeat devices'). ${ }^{75}$ After emissions certification, the operating mode deactivated to improve acceleration and fuel consumption. ${ }^{76}$ These models were then sold under the pretext of being "eco-friendly" while they were not ${ }^{77}$. The first sales of vehicles equipped with this embedded software dated back to approximately $2009^{78}$. In other words, the scandal concerning this embedded software was Union wide (even global), affected a large number of consumers in total and was only detected after a long period of time due to its technical nature. Notwithstanding possible violations in the fields of environmental law, competition law, criminal law, or whichever, this analysis only adopts a EU consumer law perspective. Several interests of consumers were harmed such as, inter alia, consumers who wanted to purchase "eco-friendly" cars were misled ${ }^{79}$, the resale value of their cars is likely to diminish after the discovery $^{80}$, their cars were subjected to software updates which increased fuel consumption and degraded their horsepower ${ }^{81}$ or as they would no longer be able to enter low-emission zones in some urban areas ${ }^{82}$.

10/documents/vw-nov-caa-09-18-15.pdf [https://perma.cc/G8WY-PWLT].

75. The Dieselgate. A Legal Perspective ix (Marco Frigessi di Rattalma ed., 2017).

76. Christian Krachler \& Martin Rzehorska, "Dieselgate" and Consumer Law: Repercussions of the Volkswagen scandal in Austria, 6 EuCML 2017 36, 36 (2017).

77. Sara Landini, Environmental Law, in The Dieselgate. A legal Perspective 159, 164 (2017).

78. Britt Blackwelder et al., The Volkswagen ScAndal 1 (Univ. of Richmond: Robins SCH. OF Bus. 2016), https://scholarship.richmond.edu/cgi/viewcontent.cgi?article=1016\&context= robins-case-network [https://perma.cc/EU9T-NPFR] (last visited Apr. 3, 2019). See also Transport \& Environment, Dieselgate. Who? What? How?, at 7 (Transport \& Env'T, 2016), https://www.transportenvironment.org/sites/te/files/publications/2016_09_Dieselgate_report_w ho_what_how_FINAL_0.pdf [https://perma.cc/QG4X-XGH5] (last visited Apr. 3, 2019).

79. Notice of Violation, supra note 77.

80. Sandra Passinhas, "Dieselgate" and Consumer Law: Repercussions of the Volkswagen scandal in Portugal, 6 EuCML 42, 43 (2017). See also Charles Miller, Volkswagen and Audi 'Clean Diesel' Owners See Decline in Vehicle Value Following VW Emissions Recall Scandal, HG.ORG Legal Resources, https://www.hg.org/legal-articles/volkswagen-and-audi-clean-dieselowners-see-decline-in-vehicle-value-following-vw-emissions-recall-scandal-36898 [https://perma.cc/RK6J-NHAU] (last visited March 25, 2019).

81. Krachler \& Rzehorska, supra note 79, at 36-37. See also Miles Brignall, Thousands of drivers suffer loss of power following VW emissions 'fix', The Guardian (Jul. 12, 2017), https://www.theguardian.com/money/2017/jul/12/drivers-loss-of-power-vw-emissions-fix-classaction [https://perma.cc/24GW-9M58] (last visited March 20, 2019).

82. See Peter Teffer, Dieselgate casts doubt over low emission zones, EUOBSERVER (Nov 18, 2016), https://euobserver.com/regions/135941 [https://perma.cc/2AVN-CKFQ] (last visited Apr. 1, 2019). Consumers' cars equipped with the Dieselgate software were categorised into a more 
To protect these consumer interests, an effective enforcement response is required. This contribution does not aim to engage in an extensive debate on the general meaning ${ }^{83}$ of effective enforcement. In simple terms it can be referred to as the implementation of law in practice ${ }^{84}$ and thus as similar to compliance. Since a sound legal basis is a necessary condition $^{85}$ for effectiveness, the assessment examines the previous (CSD) and new directive (GD) concerning goods with embedded software and whether these can (i) restore the losses suffered by all the injured consumers involved ('compensation', or 'redress') and (ii) prevent similar infringements from happening in the future by discouraging (potential) perpetrators from committing these ('deterrence'). These two objectives of enforcement ${ }^{86}$ can traditionally ${ }^{87}$ be regarded as instrumental for achieving compliance ${ }^{88}$ and thus effective enforcement.

polluting category (i.e. from EURO 5 to EURO 6) and could therefore then be banned from certain urban areas with low emission standards.

83. Cf. Fabrizio Cafaggi \& Paola Iamiceli, The Principles of Effectiveness, Proportionality and Dissuasiveness in the Enforcement of EU Consumer Law: The Impact of a Triad on the Choice of Civil Remedies and Administrative Sanctions, 25 ERPL 575, 577-81 (2017). Effectiveness as a legal principle in EU consumer law also exists but has to be distinguished from its general meaning. The latter can be applied as a benchmark for the enforcement of any substantive law provision in any legal jurisdiction.

84. See Enforcement and Effectiveness of Consumer Law 5 (Geneviève Saummier \& Hans-W. Micklitz, eds., 2018). A definition of 'effectiveness' in the field of consumer law enforcement falls outside the scope and purpose of this contribution since, as Micklitz and Saummier rightly state, "effectiveness is one of the most complicated issues to 'measure"".

85. Id.

86. NEW FRONTIERS OF CONSUMER PROTECTION: THE INTERPLAY BETWEEN PRIVATE AND PUBLIC ENFORCEMENT 2 (Fabrizio Cafaggi \& Hans-W. Micklitz eds., 2009).

87. See, e.g., Klaus Viitanen, Enforcement of consumers' collective interests by regulatory agencies in the Nordic countries, in COLlECTIVE ENFORCEMENT OF CONSUMER LAW: SECURING Compliance in Europe through Private Group Action and Public Authority INTERVENTION 83, 83-103 (Willem Van Boom \& Marco Loos eds., 2007). Compliance through soft law methods is another viable option which will not be discussed in this contribution.

88. See Louis Visscher, RECHTSECONOMISCHE BESCHOUWINGEN OVER RECHTSHANDHAVING [Considerations on enforcement from a law and economics perspective] 5 (2009), http:/hdl.handle.net/1765/31467 [https://perma.cc/C7XV-ECNY]. The successful exercise of compensatory private claims could in theory also deter traders from committing infringements and thus have a preventive effect. Compensation is of course, in our opinion, also of importance to restore the imbalance between perpetrator and victim after an infringement and thus reach implementation of law in practice. 


\section{B. Enforcement Issues in the Consumer Sales Directive and the Goods Directive}

\section{Repercussions on Enforcement of the Substantive Law Provisions}

Applying the previous Consumer Sales Directive shows that the Dieselgate scandal was a clear-cut situation of a lack of conformity of the delivered good with the contract of sale and, hence, an infringement on this requirement. The emission standards of the Dieselgate vehicles were of worse quality and performance than presented by the producer. Moreover, since the emission limits (i.e. EURO 5) were incorporated in the agreement between Volkswagen AG dealers (sellers) and consumers, one could say these were explicitly agreed upon. ${ }^{89}$ Based on Article 2.2 (d) of the previous directive, the good did not show the quality and performance that the consumer can reasonably expect, given the nature of the good and taking into account any public statements on the specific characteristics of the goods made about them by the seller, the producer or his representative, particularly in advertising or on labelling. Under the new Goods Directive, lack of conformity still seems at hand since the good didn't have the description or quality (i.e. emissions performance) as the contract of sales specifies (subjective requirement, see Article 6 (a)) nor possesses the qualities and other features the consumer may reasonably expect (objective requirement, see Article 7.1 (d)).

The time limit of two years in the previous directive turned out to be a significant issue in the aftermath of the scandal. At the time of discovery of the infringement (September 2015), most of the models equipped with the fraudulent software were already well past said time limit and thus fell outside the scope of application of the Consumer Sales Directive. ${ }^{90}$ After all, the bulk of the infringements in the EU occurred between 2010 and 2014. ${ }^{91}$ The default period of two years has unfortunately been maintained by the new directive ${ }^{92}$ (Article 10.1 GD), and some critical observations have already been made previously. Applied to Dieselgate, the two-year liability period is first of all far too short since the delivery of some models dates back to even six years (2009) before the discovery of the infringement (2015). Secondly, the success of a consumer invoking one of the four civil law remedies in a court of law mostly depends upon the presumption period. Without this presumption, the consumer has to prove that the fraudulent software was installed at the time of the delivery of the good which

89. Charles Dybus \& Jeroen Lemmen, "Dieselgate" and Consumer Law: Repercussions of the Volkswagen scandal in the Netherlands, 6 EuCML 91, 91 (2017). See also Krachler \& Rzehorska, supra note 79, at 36. The permitted exhaust emission limits were listed in the standard sales contracts of Volkswagen dealers and can therefore be considered as explicitly agreed upon by the parties.

90. See also Passinhas, supra note 83, at 43.

91. Transport \& Environment, supra note 81, at 3.

92. As seen before, this default time limit can be extended when a continuous supply of more than two years is at hand. 
creates a very heavy burden of proof due to the technical nature of the embedded software. This minimum period of the presumption is now extended from six months up until one year (Article 11.1 GD) and would still be too short in most cases. Granted, once the competent government authorities concluded that these 'defeat devices' were indeed installed at the delivery and the goods therefore lacked conformity, this issue of proof would no longer have been relevant in private proceedings. These are, however, favourable circumstances specific to the Dieselgate case and will not always arise.

The fraud by Volkswagen AG was detected by the United States supervisor on environmental law $^{93}$ and only after a period of six years due to its technical aspects. The nature of goods with embedded software thus causes detection of infringements to be difficult when it is particularly related to software. If these infringements are or were detected, it is likely this will or would only take place after some time. Moreover, it is improbable that the individual consumer has the expertise to detect infringements on such a technical level and then also prove them in court. In this respect, literature has already addressed some of these issues as pervasive barriers for individual private enforcement of consumer law. Consumers will often not exercise their rights in courts because they are unaware that an infringement is at hand or because the time-consuming and costly nature of litigation discourages them. ${ }^{94}$ Furthermore, the rational consumer will not act if the costs outweigh the benefits, for instance, when harm is very small and the investment to enforce the law is costly. ${ }^{95}$

This is no different with embedded software. If consumers invoked the remedies of the new Goods Directive, they would most likely only receive a repair of said software (e.g. an update). This was notably exemplified in Dieselgate $^{96}$ where in some cases the lack of conformity was successfully remedied in this way. ${ }^{97}$ Replacement as a remedy can only be invoked if this would not impose disproportionate costs on the seller. Consumers receiving, for instance, a new car instead of a software update can be considered as such. Only a full reimbursement of the price after termination of contract could therefore be an adequate financial incentive for an individual consumer to bring an action before a court, albeit unlikely in both the previous Consumer Sales Directive and

93. Supra note 74.

94. Kati J. Cseres, Enforcement of collective consumer interests: a competition law perspective, in COLLECTIVE ENFORCEMENT OF CONSUMER LAW: SECURING COMPLIANCE IN EUROPE through Private Group Action And Public Authority Intervention 123, 129 (Willem Van Boom \& Marco Loos eds., 2007).

95. See Michael Faure \& Franziska Weber, The Diversity of the EU Approach to Law Enforcement - Towards A Coherent Model Inspired by a Law and Economics Approach, 18 GERMAN L. J. 823, 854 (2017). This is commonly referred to as 'rational apathy'.

96. See also Thomas Riehm \& Lukas Lindner, "Dieselgate" and Consumer Law: Repercussions of the Volkswagen scandal in Germany, 6 EuCML 39, 39 (2017).

97. See Dybus \& Lemmen, supra note 92, at 91. Some Volkswagen models showed negative influences on the car's performance after the update, whilst others actually showed positive influences. 
the Goods Directive. This is namely a secondary remedy which can only be invoked if repair or replacement have failed or are unfit. Moreover, it is required that the lack of conformity is not of minor importance to have the contract rescinded ${ }^{98}$ or terminated..$^{99}$ In some cases it could be reasonable for the seller to argue that the (hidden) fraudulent software is of such minor importance. ${ }^{100}$ The other secondary remedy, a proportionate price reduction, seems more probable but the potential benefit is then much smaller. Hence, the potential benefits of litigation when embedded software is involved are also small (e.g. receiving an update) compared with the cost thereof (basic costs of the trial with an additional cost of an expertise inquiry), even when the good in itself was initially of high value and purchased at a high price (e.g. a car).

These existing barriers now seem strengthened in very technical situations ${ }^{101}$ such as goods with embedded software and this will probably become more of an issue due to the ever-growing presence of software components in consumer goods in the rapidly advancing digital age. Goods with embedded software are therefore hallmarked with an 'expertise barrier' which hinders consumers from detecting infringements in time, or even at all, and also effectively enforcing their rights in court. Furthermore, if the technical nature of goods with embedded software causes infringements to be detected only after a long period of time, it will also be more likely to harm a larger number of consumers. Hence, it seems plausible that infringements concerning embedded software could, as time passes, become widespread as well.

Like its predecessor, the Goods Directive targets liability for these infringements concerning embedded software at the seller. The producer of the fraudulent software (or update) escapes legal action by the consumer and the (retail) seller is supposed to implement a redress action according to Article 18 GD (which remained nearly identical to Article 4 of the Consumer Sales Directive). If the lack of conformity resulted "from an act or omission, including omitting to provide updates to goods with digital elements in accordance with Article 7.3 by a person in previous links of the chain of transactions, the seller shall be entitled to pursue remedies against the person or persons liable in the chain of transactions. The persons against whom the seller may pursue remedies and the relevant actions and conditions of exercise, shall be determined by national law". The provision only obligates Member States to establish this right of redress, whilst the shaping of this right and the procedures leading thereunto were left to the Member States. ${ }^{102}$

98. Council Directive 1999/44/EC, art. 3.6, 1999 O.J. (L 171) 1, 9 (EC).

99. Council Directive 2019/771, art. 13.5, 2019 O.J. (L136) 28, 44 (EU).

100. See Riehm \& Lindner, supra note 99 , at 40 . We have to emphasize, however, that some consumers might consider the ecological aspect of a car of major importance, whilst others might not.

101. See also Monika Namyslowska, "Dieselgate" and Consumer Law: Repercussions of the Volkswagen scandal in Poland, 6 EuCML 87, 90 (2017), who rightly states the Volkswagen case is complicated due to nuanced circumstances and a complex technical background.

102. Council Directive 2019/771, 2019 O.J. (L136) 28, 38 (EU). 
The retail seller (e.g. a small salesman of a brand of Volkswagen AG cars) is in this manner placed in the difficult legal position where he has to bring an action before court against the (multinational) producer (e.g. Volkswagen AG). It seems unlikely that this cascade system of liability procedures is fit to provide the necessary deterrence towards the actual potential perpetrators. To ensure compliance, deterrence requires that the perpetrators are discouraged, i.e. producers, from committing future infringements. Hence, the prevention of similar future infringements cannot be achieved when only the seller is liable to the consumer in the directive.

Granted, neither liability nor the four civil law remedies mean to impose a deterrent sanction towards the infringing perpetrator, but most of all strive to compensate consumers for the lack of conformity. ${ }^{103}$ Even so, the achievement of this compensatory objective in a court of law can only be met if the above mentioned enforcement barriers (time limit and burden of proof) are not of issue. Even if, for example, the time limit was extended, the discovery of the infringement could take some years due to its technical nature and it could be that the retail seller is no longer in business by then. A successful retail seller (e.g. of numerous Volkswagen AG models) could, moreover, go out of business when several consumers effectively exercise their remedies at the same time (e.g. through a collective redress procedure ${ }^{104}$ ). These concerns show the achievement of full compensation for all consumers seems doubtful when only sellers can be held liable. Direct and additional liability of the producer could support the achievement of actual compensation for affected consumers.

A last concern lies in the use of updates. Volkswagen AG carried out updates to correct the fraudulent software, which did not always go without problems. The repair of the original lack of conformity, i.e. emission standards, resulted in a new lack of conformity with the contract of sale in some cases, i.e. higher fuel consumption and a loss of horsepower. ${ }^{105}$ The Consumer Sales Directive did not provide any protection, but neither will the new Goods Directive since liability for updates again falls on the seller. It was also made clear previously that (even) when an update occurs (just) within the time limit of continuous supply, it offers no protection if this update shows issues. This new lack of conformity is clearly not caused by the original seller but by the producer, whilst it is again only the former who could be liable and has to commence redress actions against the latter. The above-mentioned issues are again at hand.

103. See Council Directive 1999/44/EC, 1999 O.J. (L 171) 12, 13 (EC) and Council Directive 2019/771, 2019 O.J. (L136) 28, 29, 36 (EU). Repair or replacement can be regarded as remedies which restore the lack of conformity, whilst price reduction or termination of contract offer redress by equivalence.

104. See Krachler \& Rzehorska, supra note 79, at 39. Volkswagen dealers (i.e. sellers) have been targeted by collective procedures in Austria.

105. Brignall, supra note 84. See also Krachler \& Rzehorska, supra note 79, at 37 . Conformity with the contract is not established and the buyer could then, in theory, request price reduction or rescission of contract. 


\section{Enforcement Provisions: Scope and Meaning}

The previous section shows that even the new Goods Directive would still not provide the necessary legal basis for effective enforcement if Dieselgate had happened today. The gaps in substantive law for the protection of consumer interests that existed then, remain. Regardless of these identified gaps, that is to say in the hypothesis that these would not exist, could an enforcement provision in the new Goods Directive contribute to effective enforcement?

The establishment and shaping of remedies, sanctions and procedures traditionally falls under the enforcement autonomy of Member States. ${ }^{106}$ The Consumer Sales Directive and the Goods Directive poses an exception thereon due to remedies with a compensatory objective towards sellers already being present in both directives. Apart from that, the Consumer Sales Directive did not mention enforcement, whilst Article 19 GD now additionally states: "Member States shall ensure that adequate and effective means exist to ensure compliance with this Directive". The phrase "means to ensure compliance" could include both deterrent sanctions and the procedures due to its broad formulation, but not additional compensatory measures against sellers ${ }^{107}$ since Article 4 GD prescribes maximum harmonisation. Moreover, these means have to be both adequate and effective. This condition can be interpreted through the principle of effectiveness as it is understood in consumer law enforcement. ${ }^{108}$ Effectiveness has been defined as a principle enabling an adequate remedial response to a violation in terms of both (i) the aptness of a remedy or sanction to in fact perform the function for which it is designed (preventive, penal, compensatory, restitutionary, etc.) and (ii) the absence of obstacles (mostly procedural) that in fact prevent the attainment of said objectives. Based on this definition and recent case law of the Court of Justice of the European Union regarding this same phrase, ${ }^{109}$ the seemingly separate condition of adequacy is already entailed in the phrase 'effective means'.

Article 19 furthermore says these means shall include provisions whereby one or more of three kinds of bodies, as determined by national law, may take action under national law before the courts or before competent administrative bodies to ensure that the national provisions transposing the new directive are applied. These bodies can be: (i) public bodies or their representatives, (ii) consumer organisations having a legitimate interest in protecting consumers, or (iii)

106. See also Olha Cherednychenko, Public and Private Enforcement of European Private Law: Perspectives and Challenges, 23 ERPL 481, 482 (2015).

107. See Council Directive 2019/771, 2019 O.J. (L 136) 28, 38 (EU). Member States retained the freedom to establish remedies by consumers against producers.

108. See Cafaggi \& Iamiceli, supra note 86, at 577 and 581. A further elaboration on the complex conceptual meaning of these principles falls outside the scope of this contribution.

109. Case 109/17, Bankia SA v. Juan Carlos Mari Merino and Others, CURIA (Sept. 19, 2018), $\mid$ I 35, 43. In a case on the same phrase "adequate and effective means" from Article 11 of the Unfair Commercial Practices Directive, the CJEU seemingly did not consider adequate to be a separate condition for enforcement. 
professional organisations having a legitimate interest in acting. This provision only obligates Member States to establish or appoint one of these three bodies and apt procedural provisions as to ensure the application of the directive, or in other words, to ensure compliance. This leaves room for professional organisations (e.g. of sellers) of which the provision only requires a legitimate interest in acting and not necessarily the interest of protecting consumers. The provision allows for an organisation of traders to be appointed in fulfilling this enforcement task by, for instance, bringing an injunction procedure for unfair competition. This could then also protect consumer interests.

$\mathrm{Be}$ it as it may, the vague and broad formulation of Article 19 leaves ample room to the discretion of Member States and therefore hardly, if at all, affects enforcement autonomy. ${ }^{110}$ Regarding the Dieselgate scandal, the enforcement responses differed strongly in the EU due to this autonomy and the introduction of Article 19 in the Goods Directive does not seem capable of changing this. In some Member States, collective enforcement mechanisms are possible which could constitute an effective response to compensate consumers like in the Dieselgate scandal. Fully functioning collective redress mechanisms are, however, only available in a limited number of Member States ${ }^{111}$ and even then the application of such a procedure in light of Dieselgate only benefited a limited number of consumers in comparison to the total number of affected consumers. ${ }^{112}$ In other Member States, the public watchdog (or, 'public supervisor/authority') on consumer law responded (e.g. Italy ${ }^{113}$ and the Netherlands ${ }^{114}$ ). Critical voices

110. See Case 388/13, Nemzeti Fogyasztóvédelmi Hatóság v. UPC Magyarország kft, CURIA (Apr. 16, 2015), ๆ 57. Enforcement autonomy stands firm even when directives obligate Member States to follow these principles.

111. European Collective Redress - What is the EU waiting for?, BUREAU EUROPÉENNE DES Unions DES CONSOMMATEURS 6 (Jun. 31, 2017), https://www.beuc.eu/publications/beuc-x-2017086_ama_european_collective_redress.pdf [https://perma.cc/AM3R-ULE3]. See also The EU's Response to the "dieselgate" scandal, EUROPEAN COURT OF AUDITORS, at 70-72 (February 2019) https:/www.eca.europa.eu/lists/ecadocuments/brp_vehicle_emissions/brp_vehicle_emissions_e n.pdf [https://perma.cc/63FJ-Q59J].

112. See Namyslowska, supra note 104, at 90. The involvement of Polish consumers in collective redress against Volkswagen is still relatively small compared to approx. 140.000 defective Volkswagen cars. A positive outcome of the proceedings will only satisfy the private interests of a limited number of Polish consumers. The proceedings were, moreover, based on the Unfair Commercial Practices Directive, not the Consumer Sales Directive.

113. The Italian Competition Authority fines the Volkswagen Group for tampering with their vehicles' emissions control systems, Autorità Garante della ConCorRenZa E DEL MERCATO (Aug. 8, 2016), http://en.agcm.it/en/media/detail?id=0899f747-5c9e-4642-b866-c4ac22cc60e0 [https://perma.cc/X9MD-YLLQ].

114. Besluit van de Autoriteit Consument en Markt tot het opleggen van een boete aan Volkswagen $A G$ [Decision of the Authority for Consumers \& Markets to impose a fine on Volkswagen AG], AutORITEIT CONSUMENT \& MARKT (Oct. 18, 2017), https://www.acm.nl/sites/ default/files/documents/2017-12/besluit-acm-beboet-volkswagen-ag-voor-oneerlijkehandelspraktijken-2017-12-01.pdf [https://perma.cc/MY2P-K535]. 
have rightly contended the applied sanctions were too low and therefore did not cause sufficient deterrence. ${ }^{15}$ The maximum cap of the fine was insignificant (e.g. 450.000 Euros in the Netherlands ${ }^{116}$ ) in comparison with the financial means of the perpetrator (Volkswagen AG group) and the magnitude of the infringement (i.e. approx. 8 million cars lacking conformity). The legal consequences (i.e. remedies and sanctions) should correspond with the nature of the infringement so compensation and deterrence can be fully achieved.

Dieselgate showed this fragmentation of enforcement is detrimental for the full achievement of the objectives of compensation and deterrence, but also equal consumer protection ${ }^{117}$ across the EU. Integration of the national markets within the Single Market of the European Union is ever-increasing. ${ }^{18}$ If goods with embedded software from the same producer are increasingly being retailed all across the European Union due to outlet markets of producers transcending national markets or due to its further circulation as second-hand goods, it is not unlikely Unionwide infringements like Dieselgate ${ }^{119}$ will happen more often. Hence, infringements concerning embedded software will not only be discovered after a long period of time and will therefore be widespread, they could also turn out to be Unionwide.

\section{Towards Effective Enforcement of Infringements Concerning Embedded Software}

Enforcement of Dieselgate-like infringements remains ineffective due to a defective legal basis and fragmented enforcement. An infringement like Dieselgate requires enforcement that can overcome the 'expertise barrier', is aimed at the producer and is also in correspondence with the total number of affected consumers within the European Union. This corresponding response needs to go beyond a mere compensation and should also impose a punishment by means of sanctions ${ }^{120}$ to discourage future potential offenders. Fragmentation

115. Evelyne Terryn \& Pauline Verbiest, De herziene CPC verordening als oplossing voor grensoverschrijdend consumentenleed? [The revised CPC Regulation as a solution for cross-border consumer detriment], 118 DCCR 5, 27 (2018).

116. Autoriteit CONSUMENT \& MARKT, supra note 117.

117. Collective Redress in the Member States of the European Union, PARL. EUR. Doc. (PE 608.829) 58 (Oct. 2018).

118. Intra-EU trade in goods - recent trends. Evolution of intra-EU trade in goods: 20022018, Eurostat (Sept. 2018), https://ec.europa.eu/eurostat/statistics-explained/index.php/IntraEU_trade_in_goods_-_recent_trends\#Evolution_of_intra-EU_trade_in_goods:_2002-2018 [https://perma.cc/FWF2-DSG6] (last visited Apr. 3, 2019). The intra-EU trade in goods has nearly doubled since 2002 and keeps on rising. See also Collective redress in the Member States of the European Union, supra note 120. The increasing integration requires integrated enforcement since consumers in some Member States could not get redress in the aftermath of Dieselgate.

119. See Transport \& Environment, supra note 81, at 23-24. Other car companies are also suspected of installing defeat devices.

120. See Common principles for injunctive and compensatory collective redress mechanisms 
of procedures should be avoided as they lead to unequal protection between consumers in different Member States. A single or coordinated procedural response is therefore required. The previous part showed these needs cannot be answered within the scope of the new Goods Directive. Could the answers to these needs for the effective enforcement of large-scale embedded software infringements like Dieselgate then be found outside of these directives? Indeed, both current and proposed EU legislation outside of the previously discussed directives could still provide the right solutions.

First of all, the expertise barrier could be overcome by the investigative powers and possibilities of a public enforcement body. ${ }^{121}$ Even so, it is still questionable if even such a public watchdog on consumer protection laws always has the means to detect infringements of such a technical nature as in the domain of goods with embedded software, especially when it concerns a small Member State with lesser financial means. Currently, a public watchdog from another Member State can be called upon under the provisions of the Consumer Protection and Cooperation Regulation (CPC Regulation). ${ }^{122}$ The watchdogs can then ideally aid each other within this CPC network in acquiring the necessary technical knowledge for detection and investigation. Nonetheless, it has been made clear that the effectiveness thereof depends heavily on the extent of the investigative powers of the addressed public watchdog and the procedures within the applicant ${ }^{123}$ and requested ${ }^{124}$ Member States. ${ }^{125}$ When the requested information (finally) reached the applicant authority, limitation periods for taking action in the Member State of the applicant authority had already been reached. ${ }^{126}$ Information sharing between public watchdogs has thus far not been effective and the expertise barrier in relation to goods with embedded software could not be bridged despite the CPC network.

in the Member States concerning violations of rights granted under Union law, at 17, COM (2018) 40 final (Jan. 25, 2018). Punitive damages are generally alien to the majority of the Member States' legal context. The European Commission is of the opinion these should be formally prohibited to avoid abusive proceedings.

121. Visscher, supra note 91 , at 6.

122. Regulation 2006/2004 of the European Parliament and of the Council of 27 October 2004 on cooperation between national authorities responsible for the enforcement of consumer protection laws (the Regulation on consumer protection cooperation), 2004 O.J. (L 364) 1 (2004) [hereinafter CPC Regulation].

123. 'Applicant authority' means the competent authority that makes a request for mutual assistance. See Article 3(f) CPC Regulation.

124. 'Requested authority' means the competent authority that receives a request for mutual assistance. See Article 3(g) CPC Regulation.

125. Mark Peacock et al., (External) evaluation of the Consumer Protection Cooperation Regulation, Consumer Policy Evaluation Consortium 60 (Dec. 17, 2012) http://ec.europa. eu/smart-regulation/evaluation/search/download.do;jsessionid=dQhE06qeWnqRej HtqjmPxi3 pyN5vJXqyWzuIjtBfeRZcFVCukzZp!2131975131 ?documentId=6320865 [https://perma.cc/2WWV-UAY4].

126. $I d$. 
The revised CPC Regulation (CPC2 Regulation) ${ }^{127}$ has been approved in 2017 and will enter into force in 2020 according to its Article 42. This seems to provide new possibilities that answer the discussed enforcement needs. In sum, the information sharing system has been strengthened. Article 9 provides for farreaching minimum investigative powers and, according to Article 4, limitation periods will have to be shared between the competent authorities. Furthermore, Article 11 requires that requests for information have to be answered without delay and in any event within 30 days. Other bodies which serve the interests of consumers can also be involved, which leads to the establishment of a broad information network. Article 27 states 'designated bodies' with the necessary expertise, such as European Consumer Centres, ${ }^{128}$ consumer organisations and associations and where appropriate, trader associations, ${ }^{129}$ will have the power to issue an alert to the competent authorities. These procedural innovations are encouraging for fulfilling the need to uncover and share ${ }^{130}$ technical information, which is of importance for detecting and investigating infringements concerning embedded software, in a speedy ${ }^{131}$ manner.

Apart from flaws in information sharing, the CPC Regulation also showed malfunctioning coordination procedures. ${ }^{132}$ These have therefore also been strengthened in the revised CPC2 Regulation. Strongly developed coordinated operations between public enforcement authorities and under supervision of the European Commission will be possible. The coordination is most strongly developed when a 'widespread infringement with a Union dimension' is at hand, which basically means the infringement on consumer law has spread to at least two-thirds of the Member States, accounting together for at least two-thirds of the population of the EU. The Dieselgate case can be qualified as such. ${ }^{133}$ Even within the revised CPC2 Regulation some defects ${ }^{134}$ can still be identified.

127. Regulation 2017/2394 of the European Parliament and of the Council of 12 December 2017 on cooperation between national authorities responsible for the enforcement of consumer protection laws and repealing Regulation (EC) No 2006/2004, 2017 O.J. (L 345) 1 [hereinafter CPC2 Regulation].

128. Role of the ECC-Net, European Commission, https://ec.europa.eu/info/live-work-travel$\mathrm{eu} /$ consumers/resolve-your-consumer-complaint/european-consumer-centres-network_en [https://perma.cc/E8BW-X5D8] (last visited Apr. 1, 2019). This is the so-called ECC Network.

129. In theory, trade associations of sellers could alert (embedded) software infringements to the authorities of the CPC2 network. This gives them the possibility to escape redress actions by consumers by shifting the focus to producers.

130. Albeit the information sharing procedures are only possible in a cross-border situation. Only when a competent authority suspects the same infringement has occurred or is occurring in another Member State can it request (technical) information. If it only occurs within Member State borders, then the competent authority would in principle have to fend for itself.

131. A Digital Single Market for Europe, at 5, COM (2015) 192 final (May 6, 2015). Rapid information sharing was one of the identified needs in the Digital Single Market Policy.

132. Mark Peacock et al., supra note 128, at 94 .

133. See Terryn \& Verbiest, supra note 118 , at 25.

134. Id. at 24-28. 
According to Article 17, the coordinated action procedure can only be initiated if the competent authorities of all involved Member States unanimously agree thereto. A veto right by one of these for whichever reason could thus easily undermine effective enforcement. If the coordinated action can then still commence, the European Commission will be the coordinator and more inquiries and inspections will follow. The results thereof can be adopted in a common position of the involved competent authorities if appropriate and negotiations with the perpetrator can then be initiated. According to Article 20, on the basis of the common position the competent authorities may invite the trader responsible to propose commitments to cease the infringement. The trader may also propose commitments on his own initiative which cease the infringement or offer remedial commitments to consumers.

The CPC2 Regulation seemingly offers a collective redress mechanism for consumers all over the European Union in a single procedural action, but an important defect remains: the commitments cannot be forced upon the perpetrator. The enforcement measures thereto (i.e. sanctions) still remain within the jurisdiction of the Member States. ${ }^{135}$ Deterrence is not achieved due to sanctions and procedures varying in each Member State. ${ }^{136}$ These would necessarily remain fragmented. One of the substantive consumer law directives or regulations in itself could prescribe harmonised sanctions (Article 21 CPC2 Regulation) which could then ensure deterrence (and hence compensation) if this sanction takes into account the total magnitude of the infringement across the EU.

In April 2018 the European Commission released its 'New Deal for Consumers. ${ }^{137}$ Strong emphasis was placed upon effective enforcement of consumer protection rules. The European Commission proposed a 'Modernization Directive' ${ }^{138}$ to amend several existing directives containing the EU substantive consumer law provisions, such as the Unfair Commercial Practices Directive (UCPD) ${ }^{139}$ These amendments include, among other things, a harmonisation of criteria for penalties striving towards a correspondence

135. See Cafaggi \& Iamiceli, supra note 86 , at 575 . The consumer law directives only require these sanctions are effective, proportionate and dissuasive.

136. Terryn \& Verbiest, supra note 118, at 27.

137. A New Deal for Consumers, COM (2018) 183 final (Apr. 11, 2018).

138. Proposal for a directive of the European Parliament and of the Council amending Council Directive 93/13/EEC of 5 April 1993, Directive 98/6/EC of the European Parliament and of the Council, Directive 2005/29/EC of the European Parliament and of the Council and Directive 2011/83/EU of the European Parliament and of the Council as regards better enforcement and modernisation of EU consumer protection rules, COM(2018) 185 final (Apr. 11, 2018) [hereinafter Proposal Modernization Directive].

139. Directive 2005/29/EC of the European Parliament and of the Council of 11 May 2005 concerning unfair business-to-consumer commercial practices in the internal market and amending Council Directive 84/450/EEC, Directives 97/7/EC, 98/27/EC and 2002/65/EC of the European Parliament and of the Council and Regulation (EC) No 2006/2004 of the European Parliament and of the Council ('Unfair Commercial Practices Directive'), 2005 O.J. (L 149), 22 [hereinafter $U C P D]$. 
between the nature of the infringement (e.g. gravity, duration, number of consumers harmed, intent, etc.) and the fine. ${ }^{140}$ Where the penalty to be imposed is a fine, the infringing trader's annual turnover and net profits as well as any fines imposed for the same or other infringements in other Member States shall also be taken into account in the determination of its amount. If the infringement is a widespread infringement with a Union dimension (i.e. Dieselgate) in the sense of the CPC2 Regulation, Member States have to ensure the possibility of such fines exist. These can mount up to $4 \%$ of the trader's annual turnover in the Member State or Member States concerned. It goes without saying, this would constitute a seriously deterring sanction ${ }^{141}$ due to its correspondence with the magnitude of the infringement. It could then be used to force perpetrators to propose or accept and then comply with commitments.

In the same vein, a revision of the Injunctions Directive has also been proposed. ${ }^{142}$ This directive introduces compensatory collective redress actions (i.e. 'class actions'), where a qualified entity (notably independent public bodies or consumer organisations) can represent a group of consumers who suffered losses from the same infringement. Interestingly, this procedural mechanism could aid in overcoming the expertise barrier since traders can be forced to disclose evidence in a confidential manner in a court of law or before an administrative authority. ${ }^{143}$ Moreover, cross-border representative actions would be possible: qualified entities from other Member States could bring a collective redress action before courts in other Member States and strive for redress of foreign consumers. Single collective actions representing consumers from different Member States in front of a single forum would also be a possibility. ${ }^{144}$

In other words, the $\mathrm{CPC} 2$ Regulation in conjunction with these proposals could in fact enable the establishment of legal responses which meet needs to effectively enforce Dieselgate-like infringements. When an infringing trader would, for instance, refuse collective redress through commitments and even after being forced thereto through deterrent sanctions, collective redress could still be pursued in a court of law by the same public authority.

A sound legal basis upon which any enforcement procedure must be based remains a necessary requirement for effective enforcement. The new Goods Directive still seems inadequate to address the needs for effectively enforcing infringements concerning embedded software like Dieselgate. Literature has often referred to the provisions of the $\mathrm{UCPD}^{145}$ as a solution. ${ }^{146}$ Knowingly promoting

140. Proposal Modernization Directive, Article 11(4).

141. A New Deal for Consumers, supra note 140, at 3.

142. Proposal for a directive of the European Parliament and of the Council on representative actions for the protection of the collective interests of consumers, and repealing Directive 2009/22/EC, COM (2018) 184 final (Apr. 4, 2018) [hereinafter Proposal Injunctions Directive].

143. Id. at Recital 37 and Article 13.

144. Id. at Recital 41 and Article 16.

145. UCPD, supra note 142.

146. See, e.g., Frauke Henning-Bodewig, Corporate Social Responsibility, the VW Scandal and the UCP Directive, 5 EuCML 153, 153 (2016). 
cars as "eco-friendly" whilst they are not could be regarded as misleading and could have caused the average consumer to take a transactional decision that he would not have taken otherwise. ${ }^{147}$ This was, however, another favourable circumstance, specific to this case. Volkswagen AG could as well have refrained from committing false advertising and still have equipped the concerned vehicles with fraudulent software with the goal to bypass emission standards. In other words, the qualification as a misleading commercial practice will not always offer a way out.

The practice could then still be qualified as an 'unfair' commercial practice. Under Article 5 UCPD, the trader should act in line with the requirements of professional diligence. The violation of the first condition seems fulfilled in Dieselgate since Volkswagen AG clearly, by unduly informing consumers, did not demonstrate due care. ${ }^{148}$ Additionally, it is also required the act materially distorted or was likely to distort the economic behaviour with regard to the product of the average consumer whom it reached, or to whom it was addressed, or of the average member of the group when a commercial practice is directed to a particular group of consumers. Article 2 (e) UCPD further defines "to materially distort the economic behaviour of consumers" as using a commercial practice to appreciably impair the consumer's ability to make an informed decision, thereby causing the consumer to take a transactional decision that he would not have taken otherwise. Even though the Italian public supervisor on consumer protection (Autorità Garante della Concorrenza del Marcato) referred to the breach of these provisions in the Dieselgate case due to false information concerning the emissions in certificates of conformity, ${ }^{149}$ serious doubts about the fulfilment of the conditions of this provision in this case have been made in literature. ${ }^{150}$ Whether a material distortion could have been at hand and whether this could have influenced the average consumer, can and has rightfully been called into question.

Summarily, the reliance on the broad norms of the UCPD does not seem convincing for effectively protecting consumers who are confronted with goods that lack conformity with the contract of sale, especially since this is the main objective of the new Goods Directive. ${ }^{151}$ This begs the question whether the new Goods Directive should have implemented harmonised regimes of (either) liability, remedies or sanctions aimed at the producer.

\section{CONCLUSION: CONSUMER PROTECTION 2.0 . . OR RATHER 1.1?}

It was made clear throughout the article that the previous legal context was

147. UCPD at Article 6.1. See also Terryn \& Verbiest, supra note 118, at 25.

148. Case 310/15, Vincent Deroo-Blanquart v. Sony Europe Limited, ๆ 37, 2015 CURIA (Sept. 7, 2016).

149. Supra note 116.

150. Philipp Fabbio, "Dieselgate" and Consumer Law: Repercussions of the Volkswagen scandal in Italy, 6 EuCML 94, 95 (2017).

151. Council Directive 2019/771, art. 1, 2019 O.J. (L 136) 28, 44 (EU). 
hardly appropriate in light of the ever-growing digitalisation of society. Where the Consumer Rights Directive and the national implementations thereof, to some extent, take into account the specificities of technological developments, the Consumer Sales Directive turned out to be outdated.

Even though nothing prevented Member States to adopt analogous legislative arrangements in the context of digital content and digital services (whether or not materialised), this did not happen everywhere. The consequence thereof is that immaterial digital content and services completely fell outside its scope of application. Updates also give rise to problems since lacks of conformity may be created which were not present at the moment of delivery.

These observations did not escape the attention of the Juncker Commission. To establish the development of the Digital Single Market, and thus fully take advantage of the potential of online trade and technological products, initiatives were taken for new legislative initiatives. On the one hand a new directive was adopted replacing the legal framework of the Consumer Sales Directive by a new but very comparable legal framework that, next to 'traditional' goods, also pays attention to the specificities of goods with digital elements.

Even though this attention for digital elements was without a doubt a step in the right direction, the initiatives are not yet on point. Strangely, the first part of the new directive extensively elaborates on goods with digital elements (i.e. liability and time periods), whilst the remedies remained utterly silent on that. In our opinion at least some legal arrangements of the remedies from the Digital Content Directive could have been transposed to the Goods Directive. The time limits as they are now also lack a sense of reality since the consumer loses out when the seller or third parties keep on delivering digital content or services shortly before the expiration of the period of liability which, however, brings about a new lack of conformity. An additional critical period with a variable starting point (i.e. after the last delivery of the digital content or service) would have been a welcome addition.

Additionally, these conclusions are regrettable in light of the notorious Dieselgate scandal. The previous Consumer Sales Directive was clearly inadequate to enforce this infringement. The new Goods Directive turned out to be incapable to mitigate this. Both fail to address the needs of effectively enforcing a situation where 8 million goods were delivered lacking conformity with the contract of sale caused by embedded software. Despite the new CPC2 Regulation and legislative proposals in the 'New Deal for Consumers', the main problem lies in the soundness of the legal basis which is a prerequisite for effective enforcement. Falling back on the Unfair Commercial Practices Directive did not seem convincing. In our opinion, liability of producers of the embedded software and harmonised legal consequences (i.e. remedies and sanctions) could therefore have at least been considered in the new Goods Directive, especially if Dieselgate was an omen for things to come in an increasingly integrating 'Digital Single Market'.

Whether we have now landed concerning the field of goods with digital elements in a scenario of consumer protection 2.0 or a scenario of consumer protection 1.1, should in our opinion be answered in between. One could refer to the current situation as consumer protection 1.9: even though certain steps have 
been taken in the right direction, not every imperfection has been eliminated and not every need has been addressed. Nevertheless, we can look hopeful to the future where we evolve towards a conclusive system that takes into account the needs of the digital age. The future is now. 